\title{
Viscoplastic Characterization and Modeling of Hybrid Carbon Fiber/ Carbon Nanotubes Reinforced Composites
}

\author{
A. Alipour Skandani ${ }^{1}$, M. Al-Haik ${ }^{2 *}$ \\ ${ }^{1}$ Department of Industrial Engineering, University of Pittsburgh, Pittsburgh, PA, 15261 \\ ${ }^{2}$ Department of Aerospace Engineering, Embry-Riddle Aeronautical University, Daytona
}

Beach, FL 32114

\begin{abstract}
This investigation illuminates the effect of surface grown carbon nanotubes (CNTs) on the viscoplastic behavior of fiber reinforced plastics (FRPs). The study demonstrates the feasibility of growing CNTs on conventional woven carbon fibers without degrading the fibers structural properties. The subsequent hierarchal reinforcement was utilized to fabricate laminated FRPs. The viscoplastic behaviors of the hybrid composites were investigated through series of stress relaxation and creep tests at different thermomechanical environments. The results of the experimental tests were utilized to both construct and validate a phenomenological viscoplastic constitutive model of the hybrid FRPs. The experiments and the model predictions established that surface grown CNTs could enhance the composite resistance to viscoplastic deformation.
\end{abstract}

Keyword: A. Carbon fiber, A. Nanostructures, B. Creep, B. Stress relaxation

*Corresponding author, alhaikm@erau.edu, 386-226-3736 


\section{Introduction}

Structural fiber reinforced plastic (FRP) composites including those reinforced with high performance fibers (e.g., glass, carbon, aramid or their combinations) are evolving as viable alternatives to metals for structural applications due to their elevated specific strengths and stiffness [1]. However, emerging applications of FRPs entail the exposure to elevated thermomechanical environments, which precludes their life cycles and durability, making it crucial to investigate their time/temperature dependent deformation. As embodiments of temporal thermomechanical behaviors of FRPs, creep and stress relaxation are of particular importance as they affect the strength and durability of structures made of FRPs. The deformations or changes in the material properties driven or amplified by exposure to prolonged times and/or elevated temperatures are referred to as viscoplastic deformations. Polymer matrix composites are prone to progressive deformation under constant loads (creep) and bare lesser loads under constant displacement (stress relaxation) in longer time durations. These time-dependent deformations should be accounted for in the design of FRPs structures as they could jeopardize the load bearing capacity and might induce structural instabilities.

The main source for the viscoplastic deformations in FRPs is the polymeric matrix where the constituent chains tend to slide against each other and straighten. Although the addition of carbon fibers enhances the mechanical properties of the polymers considerably - including the resistance to viscoplastic deformation other issues arise when these microscale fibers are incorporated. Straightening of the fibers from their possible initial waviness and more notably the slippage mechanisms between the fibers and matrix are major contributors to the viscoplastic deformations in FRPs.

The insufficient resistance of FRPs to viscoplastic deformations can be mitigated by the addition of nanofillers to the polymeric matrix. Nanofillers were utilized to modify the viscoplastic behavior of polymer matrix composites [2]. The presence of nanofillers could compensate for the viscous properties of polymers up to an extent; however, it brings about other changes such as reducing the ductility and altering the 
electrical/thermal properties of the composite. The amount of change depends on the volume fraction of the nanofillers, their morphology and ultimately their adhesion to the matrix. In the case of nanofillers with high intrinsic Van der Waals forces (such as carbon nanotubes; CNTs), the lack of proper dispersion becomes detrimental if the volume fraction exceeds a certain metric called the percolation threshold. The percolation threshold is considered to be the minimum volume fraction at which a filler can uniformly be dispersed in a matrix properly to form a 3D connected network throughout the matrix without agglomeration. Most research to-date focus on using CNTs as reinforcements in a polymeric matrix by shear mixing and perhaps subsequent alignment of single- or multi-walled CNTs in the matrix [3-5]. Alignment and dispersion are crucial factors that are challenging to control experimentally using oftrepeated mixing methods. Carbon nanotubes embedded in a polymeric matrix form aggregates that are not only poorly adhered to the matrix, but also concentrate stresses; compromising the contribution of the CNTs as reinforcement. Sonication [] ] and calendaring [7] have been employed to resolve this problem, but are not effective beyond $\sim 3.0 \%$ CNT volume fraction due to the formation of aggregates [ $\underline{8}]$. The extreme difficulty in uniformly dispersing CNTs in polymer matrices arises from the large surface area of CNTs [9]. Dispersion and extrusion techniques have been reported in the literature for producing CNTs composites [10]. However, in both techniques, producing uniform and well-dispersed CNTs reinforced composite is difficult because of the small amount of solid 'powder' (carbon) compared with the large amount of liquid polymer (matrix) in early mixing stages. This often leads to phase separation due to the strong van der Waals forces between CNTs compared with that between CNTs and polymer [4].

Several protocols were applied to enhance the fiber/matrix interface and, thus, hinder the slippage mechanism between the fibers and the matrix encountered in viscoplastic deformations. The chemical treatment approach utilizes acidic reagents (e.g. chlorosulforic acid, nitric acid, etc...) to attach functional groups such as carboxyl, ether or hydroxyl to the fiber to improve the load transfer and adhesion between the fiber and the matrix. It was demonstrated that the chemical treatment improves the wettability and the surface roughness of the fibers, which in return, increase the tensile strength, and the interlaminar shear 
strength of the composite [11]. However, the chemical treatments could induce excessive erosion to the fiber leading to a reduced composite strength.

An alternative approach to impede the slippage mechanism between the fibers and the matrix can be achieved via the creation of well-attached, small-scale physical obstacles on the fibers surface (i.e., whiskerization). Whiskerization can resolve the dispersability and agglomeration issues discussed earlier as no physical mixing is needed. The whiskers could be high aspect ratio crystalline silicon carbide, silicon nitride or CNTs grown on the surface of the fibers. The growth of high aspect ratio nanotubes on the fiber surface induces less stress concentration in the fiber since they induce stiffness gradient from the fiber to the matrix [12]. The growth of $1 \mathrm{D}$ carbon nanostructures (multi and single wall carbon nanotubes) and $\mathrm{ZnO}$ nanorods on commercially available carbon fibers has been demonstrated via different studies [13-15]. Carbon nanotubes were grown on carbon yarns and carbon fabrics surface using the catalytic chemical vapor deposition (CCVD) with different catalysts such as nickel, cobalt and iron at high temperatures $\left(600^{\circ} \mathrm{C}\right.$ to $\left.1000^{\circ} \mathrm{C}\right)$. Zhang et al. [16] have grown high density multiwall carbon nanotubes (MWCNTs) using the CCVD process at high temperatures $700-800^{\circ} \mathrm{C}$ on the surface of sized and un-sized carbon fibers. The results showed a $40 \%$ decrease in the tensile strength of the sized carbon fibers when exposed to $700^{\circ} \mathrm{C}$ growth environment. Identical results were observed for the un-sized fibers but at temperatures higher than $800^{\circ} \mathrm{C}$ which contrasts the important role played by the fibers sizing. Since the carbon fibers and the grown 1D nanowhiskers are of different size and nature, the term "hybrid nanocomposite" is used throughout the remaining text to address the whiskerized carbon FRPs. Several studies showed that both in plane and out of plane properties of carbon nanofiller modified carbon fiber and glass fiber polymer composites are considerably higher than pristine composites $[\underline{5}, \underline{17-28}]$.

The time-temperature dependent behavior of conventional FRPs has been studied utilizing different constitutive models that were originally designed for polymers [29-33]. Creep tests require prolonged testing time as the rate of change can be very slow (in some cases several years). Hence, different accelerated methods have been developed to predict the long-term creep behavior of polymeric materials 
using data from tests at elevated temperatures with considerably shorter durations. The time-temperature superposition (TTSP), Findley's model [34], Schapery's model [35] and polymer modified thermal activation energy theory [36] are some of the widely utilized accelerated creep testing schemes. Viscoelasticity of FRPs has been studied utilizing standard short-time creep tests at different temperatures to predict their long-term creep behavior $[\underline{31}, \underline{37}]$. Like many other mechanical properties, the creep compliance and the stress relaxation modulus (as two influential material parameters for viscoelasticity) are much weaker along the transverse direction to the fiber orientation [38]. This heightens the importance of studying the flexural creep properties in orthotropic or transversely isotropic FRPs where the axial direction is designated as the fiber direction, which exhibits the least deformation, imposed by time or temperature variations.

The goal of this study is to delineate the effects of growing CNTs on the surface of carbon fibers on the viscoplastic behavior of FRPs. In particular, the creep and the load relaxation behaviors of hybrid FRPs based on hybrid carbon fiber/CNTs reinforcements are examined under different thermomechanical environments. To quantify the change in the viscoplastic behavior, we examined the changes in the parameters of a phenomenological viscoplastic model developed by T. Gates for FRPs [39].

\section{Materials, Processing and Experimental Techniques:}

\subsection{Samples Preparation}

PAN-based woven carbon fibers with $3 \mathrm{k}$ bundles, Thornel ${ }^{\circledR} \mathrm{T} 650$ (Cytec, Inc.), were utilized as the reinforcement in this study. The sizing on the fibers was removed by placing the as -received sized fibers in a tube furnace at $550^{\circ} \mathrm{C}$ for 30 mins under inert environment (nitrogen). The de-sized fibers are afterward employed in a three-layer polymer matrix composite to further investigate the effect of the sizing removal on the mechanical properties of the composite. Carbon nanotubes were grown utilizing the graphitic structure by design (GSD) method, detailed elsewhere [15, $\underline{40-43}]$. 
The GSD method requires a thin layer of Ni to be applied on the fibers as a catalyst for the CNTs growth. The Ni layer $(2 \mathrm{~nm})$ was deposited on the de-sized carbon fibers utilizing a magnetron sputtering system (ATC Orion from AJA International). The carbon yarns were placed, separately, inside a quartz tube furnace. Three mass flow controllers were required for the three input gases: an inert gas (UHP $\left.\mathrm{N}_{2}\right)$, a hydrocarbon $\left(\mathrm{C}_{2} \mathrm{H}_{4}\right)$, and Ultra High Purity $\mathrm{H}_{2}$. The synthesis processes comprised three steps: (i) a reduction step, at $550{ }^{\circ} \mathrm{C}$ under $\mathrm{N}_{2} / \mathrm{H}_{2}$ environment, was carried out for 2 hours under atmospheric pressure to break the nickel film into nanoscale sized particles and to remove any nickel oxides, (ii) flushing of the system with nitrogen to remove the reduction byproducts and, (iii) the introduction of the "deposition mixture," which consisted of $\mathrm{N}_{2} / \mathrm{H}_{2} / \mathrm{C}_{2} \mathrm{H}_{4}$ while maintaining the temperature at $550{ }^{\circ} \mathrm{C}$. The growth time was set to 30 minutes.

Per our previous investigations [44], the uniform growth of CNTs might not be the best topology to improve the fiber matrix interface; very dense growth could prevent the matrix from infiltrating through to reach the base carbon fibers; leading to poor matrix/fiber adhesion. Hence, to overcome this hurdle, a patterned CNT growth is more favorable and can be achieved by enforcing interspacing in the catalytic nickel film. A perforated mesh template was clamped to the carbon fiber fabrics during the sputtering of nickel. The pattering was conducted utilizing a woven wire cloth, 316 SS, 90 X90 Mesh, .0035" Wire Dia, masking the sample during the Ni sputtering. Then upon utilizing the GSD technique, CNTs will grow following identical topology of the patterned Ni film.

The hybrid fabrics with uniform surface grown CNT and patterned-CNT growth were utilized to fabricate three layered composites laminates. The laminae layup arrangement was $0^{\circ} / 45^{\circ} / 90^{\circ}$. The middle layer orientation was chosen to further increase the matrix contribution to the overall mechanical properties. The matrix material was a resin-based epoxy, Aeropoxy ${ }^{\mathrm{TM}}$ manufactured by PTM\&W Industries, Inc., with glass transition temperature of $\mathrm{T}_{\mathrm{g}}=98^{\circ} \mathrm{C}$. 
The mold used for composite fabrication consisted of two aluminum parts separated by a flexible rubber sheet. The setup comprised a vacuum bag, peel ply release fabric, stacked carbon fabrics were impregnated with the epoxy (using a roller), another peel ply film, perforated release film, and breather cloth, consecutively. The 3 layers' layup was placed inside the bottom half of the mold, which is connected to the vacuum line, and the top part that has an airway (which is later connected to compressed air line) remained empty. To seal the mold from the ambient, it was placed in a hydraulic press (operated at 30 tons). While the layup being vacuumed, compressed air $(480 \mathrm{KPa})$ was applied to it by the means of flexible separator. Simultaneous use of the vacuum, compressed air, and press assures degassing of the resin while the carbon fabrics were kept intact under high pressure. The composites were left for 24 hours to cure the epoxy and then post cured at $85^{\circ} \mathrm{C}$ for an additional $4 \mathrm{hrs}$ to ensure full curing of the composite samples.

\subsection{Samples Characterization}

Electron scanning microscopy (LEO (Zeiss) 1550 field-emission SEM) was utilized to study the size and morphology of the grown CNTs as well as the possible effects of solution environment and heat-treating on the sizing of fibers. SEM was also utilized to study the inter-laminar space of composites in terms of delamination and other defects. To measure the weight/volume fraction of the fibers in different samples, a thermogravitational analyzer (TGA, TA Q50 from TA instruments) was employed under air environment. Disk shaped composite samples with $4 \mathrm{~mm}$ diameter were cut randomly from different locations of the composite plates and tested in the TGA by ramping the temperatures from room temperature to $500{ }^{\circ} \mathrm{C}$ at a rate of $20{ }^{\circ} \mathrm{C}$ per minute. The weight loss from $150{ }^{\circ} \mathrm{C}$ to $500{ }^{\circ} \mathrm{C}$ was considered as the amount of polymeric matrix which burns away during the heating.

An Instron ${ }^{\circledR}$ testing frame with an environmental chamber was employed to conduct the tensile and stress relaxation tests at $25^{\circ} \mathrm{C}, 45^{\circ} \mathrm{C}, 65^{\circ} \mathrm{C}, 85^{\circ} \mathrm{C}$. To better probe the effects of the temperature on the viscoplastic properties of the polymeric matrix of the samples, the typical application of polymer-glued G-10 tabs was replaced by a flexible aluminum sheet to grip the samples without imposing additional viscos behavior. 
Also, to minimize the heat latency of the metallic parts, smaller mechanical grips were utilized rather than the bulky hydraulic ones. The tensile and stress relaxation tests were carried out according to the ASTM D3039/D3039M and ASTM D6048 standards, respectively.

A standard dead weight creep frame was augmented with pneumatic power, $5 \mathrm{k}$ lb load cell and data acquisition system. An air cylinder with both compression and expansion capabilities was installed on a dead weight frame and compressed air was supplied to air cylinder through high pressure piping system and a 0-30 psi manual regulator. A high temperature grade extensometer was utilized to record the elongation of the samples throughout the loading and creep processes. The data acquisition system consisted of a 4 channel full/half bridge NI USB-9481 National Instruments DAQ system. An in-house LabView template was developed for calibration of the test and for data acquisition. $\mathrm{A} \pm 10.0 \mathrm{~V}$ bias was supplied to the bridge as an input and the resultant output signal was scaled to their physical quantities via the information provided from the manufacturers of extensometer and load cell.

\section{Constitutive Viscoplastic Modeling}

The model proposed by Gates and Sun $[\underline{30}, \underline{39}, \underline{45}]$ was utilized to predict the creep behavior of different samples using data from stress relaxation and quasistatic tensile tests. Assuming uniaxial loading where the model considers the composites as a homogeneous orthotropic material the total strain for elastoplastic (time-independent) constitutive relation may be written as a combination of elastic and plastic terms.

$$
\varepsilon^{t}=\varepsilon^{e}+\varepsilon^{p}
$$

Hooke's law provides the relation between elastic strain and stress, $\varepsilon^{e}=\frac{\sigma}{E}$, whereas, the plastic strain, $\varepsilon^{p}$, is expressed by a power law:

$$
\varepsilon^{p}=A(\sigma)^{n}
$$

Where $A$ and $n$ are material constants found from tensile test experimental data. For a rate-dependent constitutive relation, the total strain rate is divided into elastic and viscoplastic components, 


$$
\dot{\varepsilon}^{t}=\dot{\varepsilon}^{e}+\dot{\varepsilon}^{p}
$$

Where the elastic strain rate is

$$
\dot{\varepsilon}^{e}=\frac{\dot{\sigma}}{E}
$$

While the viscoplastic strain rate is decomposed into two terms.

$$
\dot{\varepsilon}^{v p}=\dot{\varepsilon}^{v p^{\prime}}+\dot{\varepsilon}^{v p^{\prime \prime}}
$$

Differentiating the plastic strain in elastoplastic constitutive relation, the first part of the viscoplastic term, $\dot{\varepsilon}^{v p^{\prime}}$ can be written as:

$$
\dot{\varepsilon}^{v p^{\prime}}=\left\{\begin{array}{lll}
\left\{A n(\sigma)^{n-1} \dot{\sigma}\right\} & \text { if } & \dot{\sigma}>0 \\
0 & \text { if } & \dot{\sigma} \leq 0
\end{array}\right.
$$

Utilizing the "overstress" concept provides the second part of the viscoplastic term, $\dot{\varepsilon}^{v p^{\prime \prime}}$ as,

$$
\dot{\varepsilon}^{v p^{\prime \prime}}=\left[\frac{<H>}{K}\right]^{1 / m}
$$

Where $H$ is the overstress, $<>$ are Macaulay brackets, and $K$ and $m$ are material constants found from experimental data. The overstress, $H=\left(\sigma-\sigma^{*}\right)$ is considered as a scalar quantity that relates the quasistatic stress, $o^{*}$, to the dynamic or instantaneous stress, $o$, at the same strain level, Ho and Krempel [느]. Thus,

$$
\dot{\varepsilon}^{v p^{\prime \prime}}=\left\{\begin{array}{lll}
{\left[\frac{<\sigma-\sigma^{*}>}{K}\right]^{1 / m}} & \text { if } & \sigma>\sigma^{*} \\
0 & \text { if } & \sigma \leq \sigma^{*}
\end{array}\right.
$$

The quasistatic stress is found by using previously defined elastoplastic equation 9 , while the dynamic stress is the stress resulting from the time-dependent material behavior.

$$
\varepsilon=\frac{\sigma^{*}}{E}+A\left(\sigma^{*}\right)^{n}
$$


The temperature dependent material parameters $K, m, A$, and $n$ are calculated from stress relaxation and quasistatic tensile experimental data. During the load relaxation, the quasistatic stress is constant, the total viscoplastic strain rate is zero and stress rate us negative; therefore, from equations 5 and 3 it can be concluded:

$$
\dot{\varepsilon}^{v p}=\dot{\varepsilon}^{v p^{\prime}}=-\dot{\varepsilon}^{e}
$$

Equations 8 \& 10 give:

$$
\dot{\varepsilon}^{v p}=-\frac{\dot{\sigma}}{E}=\left[\frac{\sigma-\sigma^{*}}{K}\right]^{1 / m}
$$

To determine $\dot{\sigma}$, one can apply numerical differentiation to the stress-time data from load relaxation tests. To better utilize the stress relaxation data, the $\log (\sigma)-\log \left(\dot{\varepsilon}^{v p}\right)$ curves can be plot from accelerated relaxation tests. This type of representation can generate an asymptotic value for the minimum or quasistatic stress.

\section{Results and Discussion}

Figure 1 summarizes the mechanical properties of the composites made of fibers exposed to $550{ }^{\circ} \mathrm{C}$ (for the purpose of desizing) for different duration to measure the amount of the degradation which is imposed on the fibers. It can be seen that the exposure to $550{ }^{\circ} \mathrm{C}$ for $30 \mathrm{~min}$ under inert atmosphere did not alter the mechanical properties of the fibers (and consequently the composite) considerably.

The following labeling is adopted throughout the article to identify composites based on different carbon fibers configurations:

- $\quad$ Neat (NT): Composite samples prepared form de-sized T650 fibers 
- $\quad$ Heat Treated (HT): Composite samples prepared form de-sized T650 fibers, undergone the $4 \mathrm{hrs}$ of $550^{\circ} \mathrm{C}$ heat treatment to mimic the effect of CNT growth process

- $\quad$ Substrate (SUB): Composite based on de-sized fiber cloth and sputtered with a $70 \mathrm{~nm}$ of $\mathrm{ZnO}$ amorphous layer using magnetron sputtering and after that kept $4 \mathrm{hrs}$ at $550^{\circ} \mathrm{C}$ to mimic the effect of CNT growth process. The $\mathrm{ZnO}$ film acts as a thermal barrier shield.

- $\quad$ CNT-Growth (CNT): Composite based on de-sized fibers, sputtered with a $70 \mathrm{~nm} \mathrm{ZnO}$ amorphous layer then coated with $2 \mathrm{~nm}$ of Ni layer all over the fibers and undergone the reduction and CNT growth process for $4 \mathrm{hrs}$ at $550^{\circ} \mathrm{C}$ (Figure 2(a)).

- $\quad$ Patterned-CNT-Growth (Pat-CNT): Composite based on de-sized fibers, sputtered with a $70 \mathrm{~nm}$ $\mathrm{ZnO}$ amorphous layer then coated with $2 \mathrm{~nm}$ of patterned Ni layer where Ni covers the fibers partially. The patterned Ni sputtered samples are then undergone the reduction and CNT growth process for 4 hrs at $550^{\circ} \mathrm{C}$ to get CNTs (Figure $2(b)$ ).

\subsection{Tensile Tests}

Figure 3 shows the weight fractions of the polymeric matrix extracted for each composite configuration. The weight loss prior to $150^{\circ} \mathrm{C}$ can be related to the humidity absorbed in the composites. All the samples incorporated $\sim 2.0 \mathrm{wt} \%$ moisture. It can be seen that the SUB sample possesses the lowest matrix weight fraction while the patterned CNT sample attained the highest one. Later on, the matrix volume fraction will be used to normalize the viscoplastic properties since the major contribution to time/temperature dependent response of material arises from the polymeric matrix.

Figures 4 depicts the data from the tensile tests at four different temperatures for the different composites samples. Six samples were tested at each temperature for each composite configuration and the average is reported including the standard deviation. It can be seen that the HT samples exhibited the lowest strength and elastic modulus whereas the CNT and Pat-CNT configurations attained the highest strengths and elastic 
moduli. Heat treatment of carbon fibers at elevated temperatures results in drastic changes in surface properties, and often triggers excessive pitting of the fiber surface, impairing the fiber tensile strength. In this process, the fibers' surface layers simply burn away unevenly to create pits in lines that coalesce into channels, resulting in a high surface rugosity [47]. This degradation of the fibers strength coupled with the degradation of the epoxy matrix strength at temperature close to $\mathrm{Tg}^{\circ}$ explains why the $\mathrm{HT}$ composite samples attained the lowest strength. Understandably, the neat (NT) sample been exposed to less severe thermal environment will retain most of the fibers strength and thus better composite strength compared to the HT sample. The presence of the ZnO substrate (the SUB sample) assisted in ameliorating the heatinduced damage to the fibers by acting as a thermal barrier coating (TBC).

In theory, whiskerization of the carbon fibers with CNTs (CNT sample) induces high strength interface between the fiber and the matric with more favorable adhesion compared to the $\mathrm{ZnO} /$ matrix interface. However, a dense growth of CNTs could impede the resin penetrates into the CNTs asperities present on the fiber surface, resulting in the formation of interfacial cavities which might cause premature failure of the interfacial bond as observed in the strength evolution of the CNT sample. Hence, it comes as no surprise that enforcing interspacing between the CNTs patches, as in the Pat-CNT sample, yielded the highest strength and elastic moduli compared to almost all other surface treatments (except the SUB samples) within temperature regimes of $25-85^{\circ} \mathrm{C}$. The high strength of the SUB samples can be explained on light of the higher fiber fraction of these samples. Nevertheless, the Pat-CNT samples, although high in matrix volume fraction (i.e., lesser in fiber volume fraction), they still have comparable stiffness and strength.

\subsection{Stress Relaxation}

Stress relaxation tests were carried out at four different strain levels at each temperature. The measured strains at four stress levels (related to $20 \%, 40 \% 60 \%$ and $80 \%$ of the corresponding composite's strength) were taken as constant strain levels for relaxation tests at each temperature; as the strength changes with temperature the strain levels are temperature dependent as well. Figures 5 (a-e) depict the stress relaxation 
at each stress level for the different composites configurations. It can be inferred that at the combination of elevated temperatures and higher load levels increases the amount of stress relaxation significantly.

Table 1 summarizes the percentages of the stress reduction relative to the corresponding ultimate strength of each composite at different temperatures. To fair the comparison and since the majority of viscous alternation in the FRPs come from polymeric matrix the data shown in Table 1 are also normalized with respect to the minimum volume fraction of the matrix.

As it can be seen at all temperatures/load levels the Pat-CNT sample outperformed the other composite configurations whereas the substrate sample showed the weakest resistance against time induced damage. The increased resistance to the viscous deformation in composites with MWCNTs grown on the fibers can be justified in terms of better matrix to fiber adhesion. Such improvement in the fiber/matrix interface hinders the slippage mechanisms responsible for the viscoplastic deformations particularly at higher stress levels. Comparing the sample utilizing just $\mathrm{ZnO}$ thermal barrier coating (SUB), with the HT samples with no such coating -but with the identical heat treatment -, it can be concluded that part of the enhanced quasistatic endurance of the CNT fortified samples (CNT \& Pat-CNT) is devoted to the presence of the $\mathrm{ZnO}$ thermal barrier layer (Figure 4). On the other hand, the $\mathrm{ZnO}$ layer weakens the viscoplastic properties of the composites by shielding the fiber bundles and preventing the polymer matrix to infuse properly in them (Table1 \&2).

\subsection{Creep}

Creep tests were carried out at the load levels and temperatures identical to the relaxation tests and the results are plotted for each configuration in Figure 6(a-e). It can be interpreted from the creep tests result that increasing both temperature and load level induces more time induced deformation.

Table 2 summarizes the creep percentages normalized with respect to the volume fraction of the polymer to fiber content. As it can be seen the Pat-CNT composite configuration displayed the maximum resistance 
against creep deformation. Also, the composite samples with CNTs (both uniform and patterned growth) exhibited improved resistance to viscoplastic deformation compared to the HT and SUB samples.

Inferring from both creep and stress relaxation data, the presence of the CNTs reduced the viscoplastic deformation of the composites. The better adhesion of the CNTs to the matrix due to their high surface area and the presence of the Van der Waals forces between them and the polymer matrix prevent the fibers from slipping against the matrix. However, when dense forests of CNTs are grown on the surfaces of the carbon fibers, the wettability of fibers by the polymer degrades. In order to facilitate the infusion of the polymer into the forest of the CNTs grown on the surface of the carbon fibers, enough spacing between the CNTs should be introduced by topologically controlled growth over the surface. As seen from the mechanical testing results the Pat-CNT samples outperforms the other configurations considerably. The presence of the nanofillers in the interlaminar space provides the composite with enhanced interlaminar shear strength (ILSS), the lack of which leads to delamination and poor creep resistance properties of laminated composites.

Overall, one can conclude that time/temperature induced deformations in FRPs are sensitive to fiber/matrix interface in different ways. The two competing factors of wettability and adhesion determine the interlaminar strength and hence the viscoplastic properties of the composite. Addition of uniformly grown CNTs on the surface of the carbon fibers, results in a better attachment of the fibers to the matrix while decreases the wettability of the fibers by the matrix. One way to go around this problem is conducting the patterned growth in which the volume and the covered area of the grown CNTs can be controlled such that they do not block the fibers from being fully immerged in the matrix during the fabrication process.

\subsection{Viscoplastic Model Validation}

Figure 7 shows a sample of the $\log (\sigma)-\log \left(\dot{\varepsilon}^{v p}\right)$ plot for CNT samples at $85^{\circ} \mathrm{C}$. Upon obtaining $\sigma^{*}$ by applying Gauss-Newton and nonlinear regression methods to equation 11, a logarithmic plot of the overstress versus the plastic strain rate can be plot similar to the one demonstrated in Figure 8. 
Since different load relaxation tests were carried out at various load levels, a quasistatic stress-strain curve can be created at each temperature. Fitting the mentioned curve to equation 9 in logarithmic scale, the material parameters $A$ and $n$ can be estimated. A sample curve for logarithm of plastic strain versus quasistatic stress is shown in Figure 9.

Table 3 summarizes the four material's constants for the entire composites configurations. It can be seen that at every temperature, the hybrid composite samples based on CNTs growth maintain relatively lower values of $\mathrm{m}$ and $k$, while $A$ and $n$ vary slightly between the different samples. It was stated by the model developers that the parameters $k, A$, and $n$ do not exhibit significant temperature dependency [39] while the parameter $m$ plays the most important role in the final determination of material viscoplastic response. Hence, to examine the repeatability of the obtained parameters, each load relaxation test was repeated and the mean and standard deviation of $m$ are reported in Table 3 as well.

Different approaches have been made to reduce the temperature dependency of the material parameters such as averaging the values of $m$ at different temperatures and using the average as temperature independent. Other approaches entail considering $n$ and $A$ to be constant at all temperatures [39]. However, all of these approaches are purely sensitivity analysis to ensure the model will produce a good fit for the experimental data rather than providing physical insights. Examining the results in Table 3, there is not a clear trend to how the material parameters vary with temperature; nevertheless, the hybrid composites with CNTs attain the lowest values for the parameter $m$ at most of the temperature levels.

Throughout the creep tests, the stress rate is zero so that the total strain rate can be estimated from equations 5 and 8 as:

$$
\dot{\varepsilon}^{v p}=\dot{\varepsilon}^{(i) v p}=\left[\frac{\sigma-\sigma^{*}}{K}\right]^{1 / m}
$$

Equation 12 is a first order nonlinear differential equation coupled to the nonlinear expression of quasistatic stress (equation 9), and can be solved numerically. In this study Newton method was utilized together with 
Runge-Kutta method to solve the coupled nonlinear differential equation with nonlinear equation of quasistatic stress. Figures 10-14 depict plots of the model prediction results versus the experimental data for four representative temperatures and load levels. It can be seen that at lower load/temperature combinations the model satisfactorily predicts the creep behavior, whereas at elevated load/temperature combinations the model predictions deviate considerably from the experimental creep test. Also, it should be noted that because the model treats the composite material to be homogenous and orthotropic, the effect of the nanofillers is implicitly embedded in the material parameters. Hence, the representative curves of the Figures 10-14 show reasonable agreement between the model prediction and experimental data particularly at lower load/temperature levels.

Regardless of the configuration of the fibers, the simulation of the viscoplastic model in the current study, as well as in our previous work $[\underline{48}, \underline{49}]$ and the work by Gates[ $[\underline{30}, \underline{39}, \underline{45}]$, concludes that: while the model predicts the creep at low temperature and low stress levels satisfactorily, it fails to produce an acceptable evolution of the creep at high stress levels and/or at temperatures close to the $\mathrm{Tg}^{\circ}$ of the composite. The viscoplastic model is phenomenological in nature; a number of tests with different loading conditions (tensile and relaxation) should be performed over reasonable levels of temperature-stress environments, such that the internal parameters of the model can be extracted. There are no clear trends on how the parameters are affected by the temperature. Moreover, the viscoplastic creep model carried out in this study is not expected to provide explicit description of all the many rate-dependent phenomena that may occur in polymer-based composites at elevated temperatures.

In particular, to this study, the NT sample and the Pat-CNT preserve the adhesion and strength better than the HT and CNT samples by facilitating either less degradation of the fiber properties (NT) or by enhancing the interfacial properties (Pat-CNT) and, thus, they hinder the viscoplastic behavior. The HT sample encountered more fiber damage and the CNT sample hindered the epoxy penetration through and, thus, both of them possessed poor adhesion to the matrix and consequently more noticeable viscoplastic 
degradation. This poor adhesion is not accounted for (explicitly) in the model, and is responsible for the discrepancy between the experimental date and the simulation for the HT and CNT samples.

\section{Conclusions}

A comprehensive experimental investigation was conducted to elucidate the viscoplastic behavior of hybrid polymer matrix composites based on carbon fiber/CNTs reinforcements. Different configurations of carbon fiber reinforced composites were fabricated with CNTs grown on their surfaces. Both stress relaxation and creep tests together with quasistatic tensile tests were performed at four different temperatures below the glass transition of the epoxy matrix. It was shown that hybridization the carbon fiber with CNTs increases the adhesion to the matrix and makes the composites more resistant to the slippage phenomena that occur during the creep deformation. This also increases the magnitude of the interlaminar shear strength which is a crucial factor in the delayed failure of the laminated composites. Moreover, the nanofiller embedded in the polymer matrix modify the viscous properties of the polymer itself. The results suggest that, a patterned growth of the CNTs on the carbon fibers enhances the infusion of the polymeric matrix into the carbon fibers and thus it outperformed the other composites configurations in alleviating the creep deformation and stress relaxation.

A phenomenological viscoplastic model was utilized to predict the creep behavior of the different composites configurations. The advantages of the model are: utilizing a very short stress/time data to predict the long term creep behavior and assuming the material to be orthotropic and homogenous which eliminates the need of costly and complicated homogenization techniques for nano composites. However, because the model assumes that the behavior of the composite is uniform over different temperatures and stress levels, it over-predicts the composites viscoplastic response at elevated temperature/load levels. Despite the unclear trend of the effect of the CNTs on the model parameters, the model predictions of the creep for hybrid composites were in good agreement (at lower load/temperature levels) with the experimental data. 
Although no clear regression to how the model's parameters vary with temperature or the fiber surface treatment; the hybrid composites with surface grown CNTs possess the lowest value for the parameter $m$ at most temperature levels, and consequently, exhibit the least viscoplastic deformation.

\section{Acknowledgements}

This work has been supported by the Office of Naval Research (ONR) Grant\# 10960991 and the National Science Foundation (NSF) award CMMI- 0846589. Dr. Al-Haik gratefully acknowledges these support.

\section{References}

[1] Hyer MW. stress analysis of fiber reinforced composite materials. USA: DEStech publications; 2009.

[2] Guo C, Zheng Z, Zhu Q, Wang X. Preparation and Characterization of Polyurethane/ZnO Nanoparticle Composites. Polymer-Plastics Technology and Engineering. 2007;46(12):1161-6.

[3] Choi E, Al-Haik M, Garmestani H, al e. Enhancement of Thermal and Electrical Properties of Carbon Nanotube Polymer Composites by Magnetic Field Processing. Journal of Applied Physics. 2003; 94.

[4] Garmestani H, Al-Haik MS, K. Dahmen ea. Epoxy Mediated Alignment of Single Wall Carbon Nanotubes Under High Magnetic Fields. Advanced Materials. 2003;15 (22).

[5] Soliman E, Al-Haik M, Taha MR. On and off-axis tension behavior of fiber reinforced polymer composites incorporating multi-walled carbon nanotubes. Journal of Composite Materials. 2012;46(14):1661-75.

[6] Jin L, Bower C, Zhou O. Alignment of Carbon Nanotubes in a Polymer Matrix by Mechanical Stretching. Applied Physics Letters. 1998;73:1197-9.

[7] Gojny FH, Wichmann MHG, Köpke U, Fiedler B, Schulte K. Carbon Nanotube-Reinforced EpoxyComposites: Enhanced Stiffness and Fracture Toughness at Low Nanotube Content. Composites Science and Technology,. 2004;64:2363-71.

[8] Garcia E, Wardle BL, deVillori RG, Wicks S, Ishiguro K, Yamamoto N, et al. Aligned Carbon Nanotube Reinforcement of Advanced Composite Ply Interfaces. 49th AIAA/ASME/ASCE/AHS/ASC Structures, Structural Dynamics, and Materials Conference 16t. Schaumburg, IL2008.

[9] Xia Z, Curtin WA, Li H, B.W. Sheldon, Liang J, Chang B, et al. Direct observation of toughening mechanisms in carbon nanotube ceramic matrix composites. Acta Materialia. 2004;52(4):931-44.

[10] Li YL, Kinloch IA, Windle AH. Science. 2004;304.

[11] Park MK. Effect of acidic anode treatment on carbon fibers for increasing fiber matrix adhesion and its relationship to interlaminar shear strength of composites. Journal of Material Science. 2000;35:1901-5. 
[12] E. Bekyarova ETT, A. Yu, H. Kim, J. Gao, J. Tang, H. T. Hahn, T.-W. Chou, M. E. Itkis and R. C. Haddon. Multiscale Carbon Nanotube-Carbon Fiber Reinforcement for Advanced Epoxy Composites. Langmuir. 2007;23:3970-4.

[13] Alipour Skandani A, Masghouni N, Case SW, Leo DJ, Al-Haik M. Enhanced vibration damping of carbon fibers-ZnO nanorods hybrid composites. Applied Physics Letters. 2012;101(7):073111.

[14] Skandani AA, Masghouni N, Al-Haik M. Superior Damping of Hybrid Carbon Fiber Composites Grafted by ZnO Nanorods. Topics in Modal Analysis. 2012;7:187-93.

[15] Al-Haik M, Dai J, Garcia D, Chavez J, Taha MR, Luhrs C, et al. Novel Growth of Multiscale Carbon Nanofilaments on Carbon and Glass Fibers. Nanoscience and Nanotechnology Letters. 2009;1:122-7.

[16] Zhang Q, Liu J, Sager R, Dai L, Baur J. Hierarchical composites of carbon nanotubes on carbon fiber: Influence of growth condition on fiber tensile properties. Composites Science and Technology. 2009;69(5):594-601.

[17] Chen Q, Zhao Y, Zhou Z, Rahman A, Wu X-F, Wu W, et al. Fabrication and mechanical properties of hybrid multi-scale epoxy composites reinforced with conventional carbon fiber fabrics surface-attached with electrospun carbon nanofiber mats. Composites Part B: Engineering. 2013;44(1):1-7.

[18] Zhou HW, Mishnaevsky L, Yi HY, Liu YQ, Hu X, Warrier A, et al. Carbon fiber/carbon nanotube reinforced hierarchical composites: Effect of CNT distribution on shearing strength. Composites Part B: Engineering. 2016;88:201-11.

[19] Zhou HW, Mishnaevsky L, Yi HY, Liu YQ, Hu X, Warrier A, et al. Carbon fiber/carbon nanotube reinforced hierarchical composites: Effect of CNT distribution on shearing strength. Composites Part BEngineering. 2016;88:201-11.

[20] Park JM, Kwon DJ, Wang ZJ, Roh JU, Lee WI, Park JK, et al. Effects of carbon nanotubes and carbon fiber reinforcements on thermal conductivity and ablation properties of carbon/phenolic composites. Composites Part B-Engineering. 2014;67:22-9.

[21] Muthu J, Dendere C. Functionalized multiwall carbon nanotubes strengthened GRP hybrid composites: Improved properties with optimum fiber content. Composites Part B-Engineering. 2014;67:84-94.

[22] Mujika F, Vargas G, Ibarretxe J, De Gracia J, Arrese A. Influence of the modification with MWCNT on the interlaminar fracture properties of long carbon fiber composites. Composites Part B-Engineering. 2012;43(3):1336-40.

[23] Liu XQ, Shen SQ, Wen R, Yang W, Xie BH, Yang MB. Reinforcement and plasticization of PMMA grafted MWCNTs for PVDF composites. Composites Part B-Engineering. 2013;53:9-16.

[24] Korayem AH, Li CY, Zhang QH, Zhao XL, Duan WH. Effect of carbon nanotube modified epoxy adhesive on CFRP-to-steel interface. Composites Part B-Engineering. 2015;79:95-104. 
[25] Hu N, Li Y, Nakamura T, Katsumata T, Koshikawa T, Arai M. Reinforcement effects of MWCNT and VGCF in bulk composites and interlayer of CFRP laminates. Composites Part B-Engineering. 2012;43(1):3-9.

[26] Chatzigeorgiou G, Seidel GD, Lagoudas DC. Effective mechanical properties of "fuzzy fiber" composites. Composites Part B-Engineering. 2012;43(6):2577-93.

[27] Boroujeni AY, Tehrani M, Nelson AJ, Al-Haik M. Hybrid carbon nanotube-carbon fiber composites with improved in-plane mechanical properties. Composites Part B-Engineering. 2014;66:475-83.

[28] Bhardwaj G, Upadhyay AK, Pandey R, Shukla KK. Non-linear flexural and dynamic response of CNT reinforced laminated composite plates. Composites Part B-Engineering. 2013;45(1):89-100.

[29] Ascione L, Berardi VP, D'Aponte A. A Viscoelastic Constitutive Law For FRP Materials. International Journal for Computational Methods in Engineering Science and Mechanics. 2011;12(5):225-32.

[30] Gates TS. Experimental Characterization Nonlinear Rate Dependent Behavior in Advanced Polymer Matrix Composites. Experimental Mechanics. 1992;32:68-73.

[31] Miyano Y, Kanemitsu M, Kunio T, Kunh H. Role of Matrix Resin on Fracture Strengths of Unidirectional CFRP. Journal of Composite Materials. 1986;20:520-38.

[32] Aboudi J, Cederbaum G. Analysis of Viscoelastic Laminated Composite Plates. Composite Structures. $1989 ; 12: 243-56$.

[33] Scott DW, Lai JS, Zureick A-H. Creep Behavior of Fiber-Reinforced Polymeric Composites: A Review of the Technical Literature. Journal of Reinforced Plastics and Composites. 1995;14:588-617.

[34] Findley WN. Mechanism and Mechanics of Creep of Plastics. SPEJ. 1960;16:57-65.

[35] Schapery RA. A Theory of Non-linear Thermoviscoelasticity Based on Irreversible Thermodynamics. Proceedings of The Fifth US National Congress in Applied Mechanics, ASME. 1966.

[36] Raghavan J, Meshii M. Creep of polymer composites Composites Science and Technology 1998;57(12):1673-88.

[37] Goertzen WK, Kessler MR. Creep behavior of carbon fiber/epoxy matrix composites. Materials Science and Engineering: A. 2006;421(1-2):217-25.

[38] Abdel-Magid B, Lopez-Anido R, Smith G, Trofka S. Flexure creep properties of E-glass reinforced polymers. Composite Structures. 2003;62(3-4):247-53.

[39] Gates TS, Sun CT. Elastic/viscoplastic consitutive model for fiber reinforced thermoplastic composites. AIAA. 1991;29(3):457.

[40] Phillips J, Shiina T, Nemer M, Lester K. Graphitic structures by design. Langmuir. 2006;22(23):9694703.

[41] Tehrani M, Safdari M, Boroujeni AY, Razavi Z, Case SW, Dahmen K, et al. Hybrid carbon fiber/carbon nanotube composites for structural damping applications. Nanotechnology. 2013;24(15). 
[42] Tehrani M, Boroujeni AY, Luhrs C, Phillips J, Al-Haik MS. Hybrid Composites Based on Carbon Fiber/Carbon Nanofilament Reinforcement. Materials. 2014;7(6):4182-95.

[43] Luhrs CC, Garcia D, Tehrani M, Al-Haik M, Taha MR, Phillips J. Generation of carbon nanofilaments on carbon fibers at 550 degrees C. Carbon. 2009;47(13):3071-8.

[44] Boroujeni AY, Tehrani M, Nelson AJ, Al-Haik M. Hybrid carbon nanotube-carbon fiber composites with improved in-plane mechanical properties. Composites Part B: Engineering. 2014;66:475-83.

[45] Gates TS. Effects of elevated temperature on the viscoplastic modeling of graphite/polymeric composites: American Society for Testing and Material ASTM; 1933.

[46] Ho K, Krempl E. Extension of the viscoplasticity theory based on overstress (VBO) to capture nonstandard rate dependence in solids. International Journal of Plasticity. 2002;18:851.

[47] Kim JK, Mai YW. Engineered Interfaces in Fiber reinforced Composites. Oxford, UK: Elseviet Science Ltd.; 1998.

[48] Al-Haik MS, Garmestani H, Savran A. Explicit and implicit viscoplastic models for polymeric composite. International Journal of Plasticity. 2004;20(10):1875-907.

[49] Al-Haik M, Vaghar MR, Garmestani H, Shahawy M. Viscoplastic analysis of structural polymer composites using stress relaxation and creep data. Composites Part B-Engineering. 2001;32(2):165-70. 
Table 1. Normalized percentage of stress reduction after 15 mins for the different composites configurations.

\begin{tabular}{|c|c|c|c|c|c|c|}
\hline & & NT & p-CNT & SUB & CNT & HT \\
\hline \multirow{8}{*}{$20 \%$} & $25^{\circ} \mathrm{C}$ & 1.059342 & 0.668275 & 1.11975 & 0.918513 & 0.868584 \\
\hline & \pm & 0.182296 & 0.164066 & 0.200526 & 0.222806 & 0.192423 \\
\hline & $45^{\circ} \mathrm{C}$ & 1.913202 & 1.434373 & 1.758871 & 1.608852 & 1.607032 \\
\hline & \pm & 0.429189 & 0.213527 & 0.136657 & 0.448407 & 0.219933 \\
\hline & $65^{\circ} \mathrm{C}$ & 2.296914 & 1.905199 & 2.152696 & 2.487673 & 2.47688 \\
\hline & \pm & 0.234162 & 0.127725 & 0.234162 & 0.332084 & 0.489611 \\
\hline & $85^{\circ} \mathrm{C}$ & 4.026611 & 2.836245 & 3.672515 & 2.923179 & 4.097273 \\
\hline & \pm & 0.667715 & 0.26128 & 0.667715 & 0.667715 & 0.589331 \\
\hline \multirow{8}{*}{$40 \%$} & $25^{\circ} \mathrm{C}$ & 1.766245 & 1.362406 & 2.710048 & 1.433585 & 2.058689 \\
\hline & \pm & 0.222806 & 0.303827 & 0.243061 & 0.206602 & 0.243061 \\
\hline & $45^{\circ} \mathrm{C}$ & 2.652005 & 2.15709 & 3.205849 & 2.592039 & 2.651244 \\
\hline & \pm & 0.256232 & 0.427054 & 0.23488 & 0.427054 & 0.190039 \\
\hline & $65^{\circ} \mathrm{C}$ & 4.361795 & 2.736171 & 5.193413 & 3.995485 & 3.883592 \\
\hline & \pm & 0.65991 & 0.255449 & 0.447036 & 0.540701 & 0.65991 \\
\hline & $85^{\circ} \mathrm{C}$ & 6.227166 & 3.52668 & 7.327485 & 4.650827 & 7.090168 \\
\hline & \pm & 0.899963 & 0.435466 & 0.841901 & 0.464497 & 0.734486 \\
\hline \multirow{8}{*}{$60 \%$} & $25^{\circ} \mathrm{C}$ & 3.556796 & 2.151806 & 5.437709 & 2.41281 & 4.263741 \\
\hline & \pm & 0.202551 & 0.243061 & 0.204577 & 0.648163 & 0.407128 \\
\hline & $45^{\circ} \mathrm{C}$ & 4.229969 & 3.285414 & 5.93619 & 3.841289 & 4.595969 \\
\hline & \pm & 0.405701 & 0.326696 & 0.32029 & 0.683286 & 0.661934 \\
\hline & $65^{\circ} \mathrm{C}$ & 5.715676 & 3.568918 & 8.641025 & 6.420151 & 5.103873 \\
\hline & \pm & 0.489611 & 0.425749 & 0.532186 & 1.198483 & 0.74506 \\
\hline & $85^{\circ} \mathrm{C}$ & 7.896453 & 4.845896 & 12.40643 & 6.581185 & 9.289945 \\
\hline & \pm & 0.958026 & 0.609653 & 1.016088 & 0.899963 & 0.699649 \\
\hline $80 \%$ & $25^{\circ} \mathrm{C}$ & 4.814638 & 3.398118 & 10.20608 & 3.842479 & 5.696185 \\
\hline
\end{tabular}




\begin{tabular}{|c|c|c|c|c|c|c|}
\hline & \pm & 0.425357 & 0.627908 & 0.445612 & 0.830459 & 0.93301 \\
\cline { 2 - 7 } & $45^{\circ} \mathrm{C}$ & 5.713981 & 4.837782 & 11.63207 & 5.793113 & 6.950715 \\
\cline { 2 - 7 } & \pm & 0.619228 & 0.491112 & 0.427054 & 0.619228 & 0.503924 \\
\cline { 2 - 7 } & $65^{\circ} \mathrm{C}$ & 5.990284 & 5.236189 & 16.82842 & 5.757496 & 7.542014 \\
\cline { 2 - 7 } & & 0.65991 & 0.276737 & 0.319312 & 1.341108 & 1.0665 \\
\cline { 2 - 7 } & $85^{\circ} \mathrm{C}$ & 9.385748 & 5.924324 & 23.77193 & 6.954356 & 12.39058 \\
\cline { 2 - 6 } & \pm & 1.306399 & 0.464497 & 1.480585 & 1.454457 & 1.744768 \\
\hline
\end{tabular}


Table 2. Normalized percentage of creep after 15 mins for the different composites configurations.

\begin{tabular}{|c|c|c|c|c|c|c|}
\hline & & NT & p-CNT & Sub & CNT & HT \\
\hline \multirow{8}{*}{$20 \%$} & $25^{\circ} \mathrm{C}$ & 0.919422 & 0.857499 & 1.007407 & 1.293726 & 0.933761 \\
\hline & \pm & 0.106077 & 0.267769 & 0.196566 & 0.312155 & 0.166315 \\
\hline & $45^{\circ} \mathrm{C}$ & 1.440493 & 0.888466 & 1.375887 & 1.499457 & 0.94134 \\
\hline & \pm & 0.293132 & 0.191679 & 0.272656 & 0.189591 & 0.190859 \\
\hline & $65^{\circ} \mathrm{C}$ & 1.540948 & 1.080037 & 1.530769 & 1.73784 & 2.511946 \\
\hline & \pm & 0.248746 & 0.102907 & 0.229724 & 0.210701 & 0.218759 \\
\hline & $85^{\circ} \mathrm{C}$ & 2.098429 & 1.084969 & 1.748201 & 1.950243 & 2.552874 \\
\hline & \pm & 0.221929 & 0.177544 & 0.291679 & 0.38045 & 0.348746 \\
\hline \multirow{8}{*}{$40 \%$} & $25^{\circ} \mathrm{C}$ & 2.225635 & 1.241896 & 1.481481 & 1.383836 & 1.21874 \\
\hline & \pm & 0.103716 & 0.167097 & 0.230479 & 0.276575 & 0.259289 \\
\hline & $45^{\circ} \mathrm{C}$ & 2.224122 & 1.718059 & 3.617021 & 1.787108 & 1.27461 \\
\hline & \pm & 0.138287 & 0.172859 & 0.190145 & 0.339956 & 0.149811 \\
\hline & $65^{\circ} \mathrm{C}$ & 2.534919 & 1.73595 & 5.776923 & 2.002654 & 2.87518 \\
\hline & \pm & 0.121001 & 0.167097 & 0.305385 & 0.201669 & 0.109478 \\
\hline & $85^{\circ} \mathrm{C}$ & 3.005857 & 1.903627 & 6.23741 & 3.287415 & 2.880296 \\
\hline & \pm & 13.25254 & 0.195907 & 0.167097 & 0.144049 & 0.299623 \\
\hline \multirow{7}{*}{$60 \%$} & $25^{\circ} \mathrm{C}$ & 3.7728 & 1.827361 & 3.237037 & 2.040353 & 1.934219 \\
\hline & \pm & 0.111748 & 0.205852 & 0.088222 & 0.329363 & 0.094104 \\
\hline & $45^{\circ} \mathrm{C}$ & 3.797141 & 2.440607 & 4.212766 & 3.831267 & 2.572607 \\
\hline & \pm & 0.147037 & 0.123511 & 0.147037 & 0.141156 & 0.135274 \\
\hline & $65^{\circ} \mathrm{C}$ & 4.416993 & 2.520087 & 6.530769 & 2.405392 & 2.9775 \\
\hline & \pm & 0.247022 & 0.264667 & 0.264667 & 0.299956 & 0.123511 \\
\hline & $85^{\circ} \mathrm{C}$ & 5.540986 & 2.934348 & 6.42446 & 4.14668 & 4.51741 \\
\hline
\end{tabular}




\begin{tabular}{|c|c|c|c|c|l|l|}
\hline & \pm & 0.169916 & 0.299956 & 0.323481 & 0.35877 & 0.182326 \\
\hline \multirow{8}{*}{$80 \%$} & $25^{\circ} \mathrm{C}$ & 3.84889 & 2.330033 & 5.192593 & 4.267364 & 4.46265 \\
\cline { 2 - 7 } & \pm & 0.260886 & 0.243871 & 0.300586 & 0.249543 & 0.425357 \\
\cline { 2 - 7 } & $45^{\circ} \mathrm{C}$ & 5.756212 & 2.531594 & 6.503546 & 4.45553 & 4.677467 \\
\cline { 2 - 7 } & \pm & 0.136114 & 0.221186 & 0.243871 & 0.068057 & 0.226857 \\
\cline { 2 - 7 } & $65^{\circ} \mathrm{C}$ & 5.857956 & 2.96887 & 8.707692 & 4.888021 & 5.059704 \\
\cline { 2 - 7 } & \pm & 0.272229 & 0.200769 & 0.482071 & 0.3176 & 0.306257 \\
\cline { 2 - 7 } & $85^{\circ} \mathrm{C}$ & 6.164843 & 3.304224 & 11.00719 & 4.634241 & 5.402474 \\
\cline { 2 - 7 } & \pm & 0.487743 & 0.453714 & 0.255214 & 0.255214 & 0.272229 \\
\hline
\end{tabular}


Table 3. Material Parameters $m, K, n$, and $A$ for the different composite configurations.

\begin{tabular}{|c|c|c|c|c|c|c|}
\hline & NT & HT & SUB & CNT & Pat-CNT \\
\hline \multirow{5}{*}{$25^{\circ} \mathrm{C}$} & $\mathrm{m}$ & 0.9895 & 1.255 & 0.99 & 1.302 & 1.01 \\
\hline & m_stdv & 0.0265 & 0.145 & 0.1 & 0.062 & 0.13 \\
\hline & $\mathrm{K}$ & $0.5 \mathrm{E} 08$ & $0.6 \mathrm{E} 08$ & $1.0 \mathrm{E} 08$ & 4.0E08 & $0.8 \mathrm{E} 07$ \\
\hline & $\mathrm{n}$ & 1.0 & 1.1 & 1.1 & 1.1 & 1.1 \\
\hline & A & 9E-07 & 5E-07 & $3 \mathrm{E}-07$ & 2E-07 & $6 \mathrm{E}-07$ \\
\hline \multirow{5}{*}{$45^{\circ} \mathrm{C}$} & $\mathrm{m}$ & 0.87 & 0.845 & 0.95 & 0.7735 & 0.796667 \\
\hline & m_stdv & 0.09 & 0.025 & 0.01 & 0.0495 & 0.08 \\
\hline & $\mathrm{K}$ & $0.1 \mathrm{E} 06$ & $0.3 \mathrm{E} 06$ & $1.0 \mathrm{E} 06$ & $0.2 \mathrm{E} 06$ & $0.2 \mathrm{E} 06$ \\
\hline & $\mathrm{n}$ & 1.1 & 1.0 & 0.9 & 1.1 & 1.1 \\
\hline & A & $5 \mathrm{E}-07$ & $1 \mathrm{E}-06$ & $5 \mathrm{E}-06$ & 4E-07 & $5 \mathrm{E}-08$ \\
\hline \multirow{5}{*}{$65^{\circ} \mathrm{C}$} & $\mathrm{m}$ & 0.88 & 0.795 & 0.715 & 1.04 & 0.395 \\
\hline & m_stdv & 0.18 & 0.125 & 0.075 & 0.06 & 0.065 \\
\hline & $\mathrm{k}$ & $3.2 \mathrm{E} 06$ & $0.6 \mathrm{E} 06$ & $1.0 \mathrm{E} 05$ & $1.2 \mathrm{E} 08$ & $1.0 \mathrm{E} 04$ \\
\hline & $\mathrm{n}$ & 1.0 & 1.0 & 1.5 & 1.0 & 1.0 \\
\hline & $\bar{A}$ & $8 \mathrm{E}-07$ & $5 \mathrm{E}-06$ & 2E-09 & 1E-06 & $1 \mathrm{E}-06$ \\
\hline \multirow{5}{*}{$85^{\circ} \mathrm{C}$} & $\mathrm{m}$ & 1.415 & 1.405 & 1.09 & 0.616 & 0.565 \\
\hline & m_stdv & 0.265 & 0.105 & 0.12 & 0.164 & 0.065 \\
\hline & $\mathrm{k}$ & $2.5 \mathrm{E} 08$ & $1.6 \mathrm{E} 08$ & 1.7E06 & $0.9 \mathrm{E} 05$ & $0.2 \mathrm{E} 05$ \\
\hline & $\mathrm{n}$ & 0.9 & 0.7 & 1.0 & 1.0 & 0.9 \\
\hline & A & $1 \mathrm{E}-05$ & $6 \mathrm{E}-05$ & $2 \mathrm{E}-06$ & 6E-06 & $1 \mathrm{E}-05$ \\
\hline
\end{tabular}



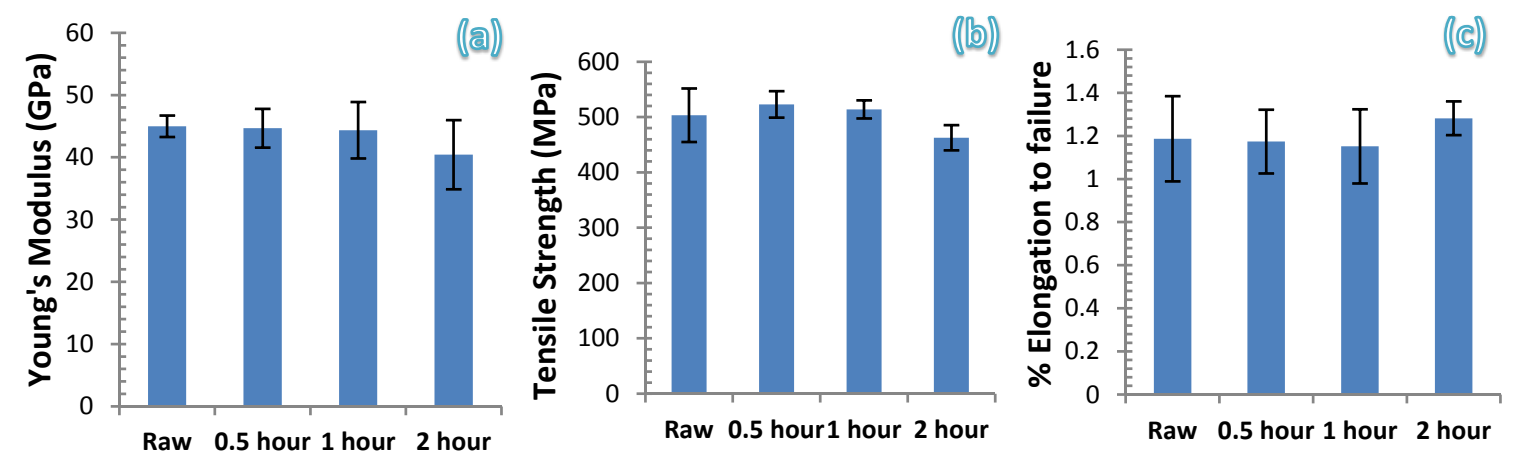

Figure 1. Effect of the duration of exposure to high temperature on the composite a) Elastic moduli, b) Ultimate strength and c) Elongation to failure. 


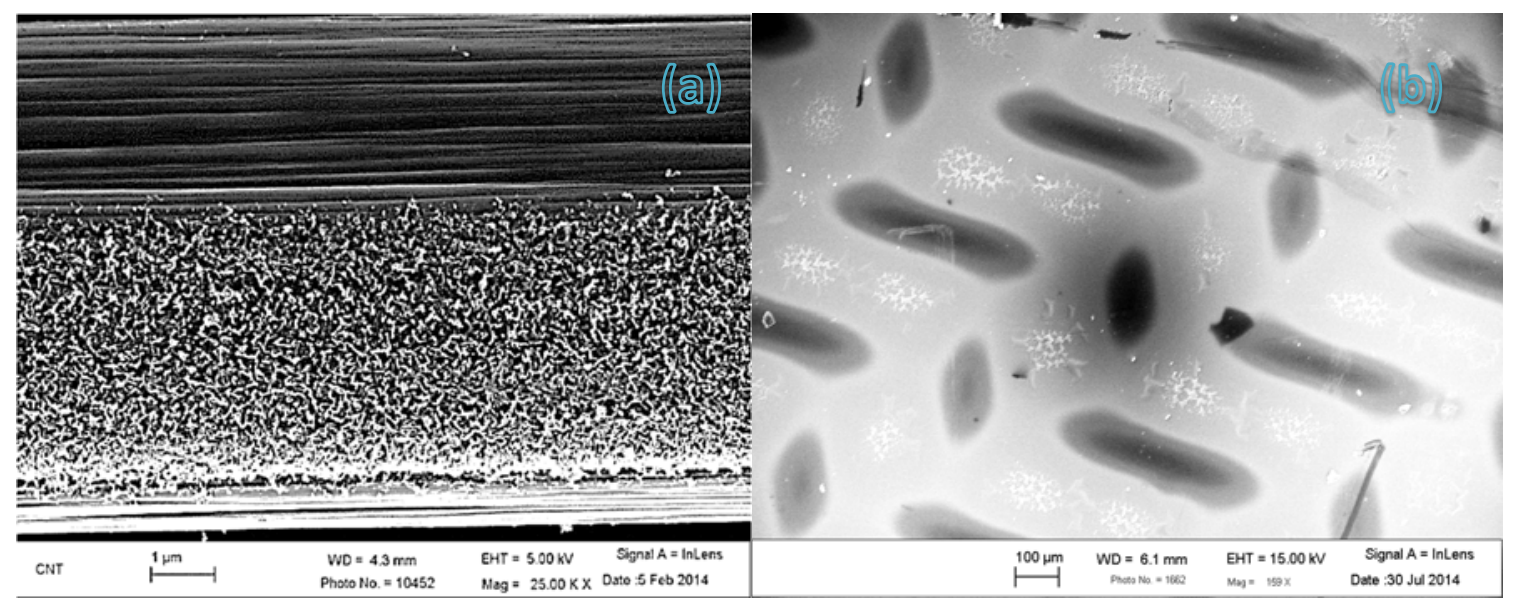

Figure 2. Different configurations of CNTs growth (a) uniform CNT growth and (b) patterned CNT growth (Pat-CNT). 


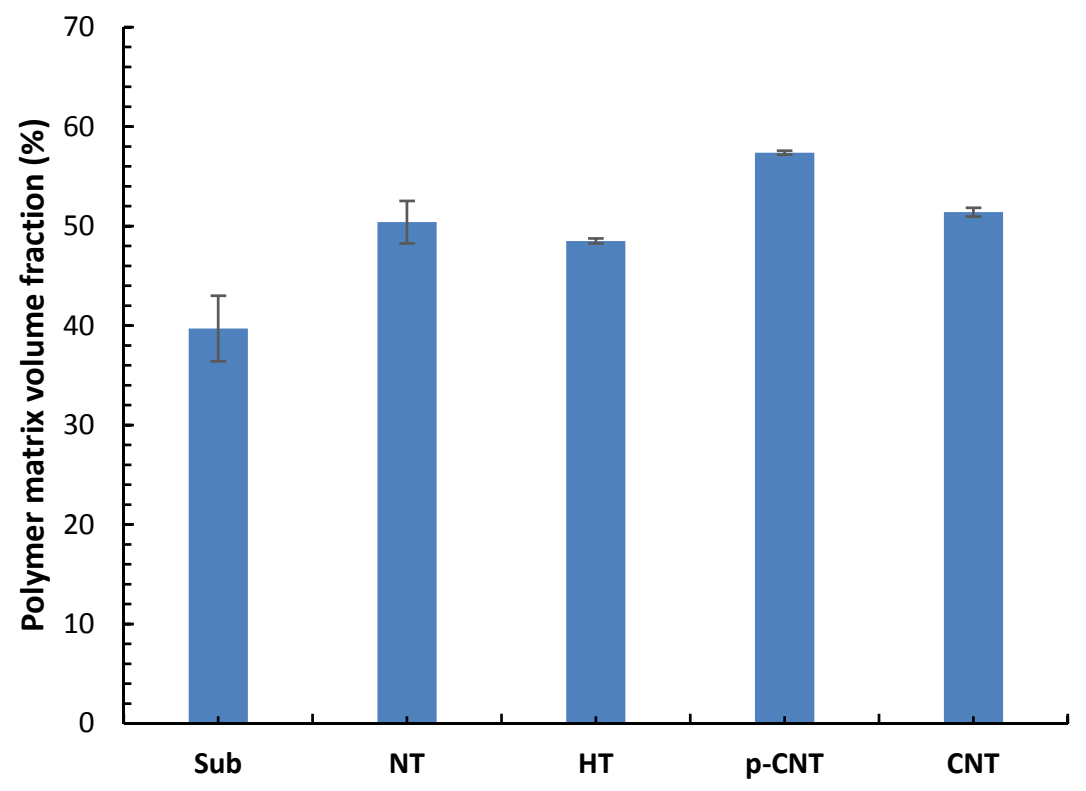

Figure 3. Weight fraction of the epoxy matrix in the different composite configurations obtained via TGA. 

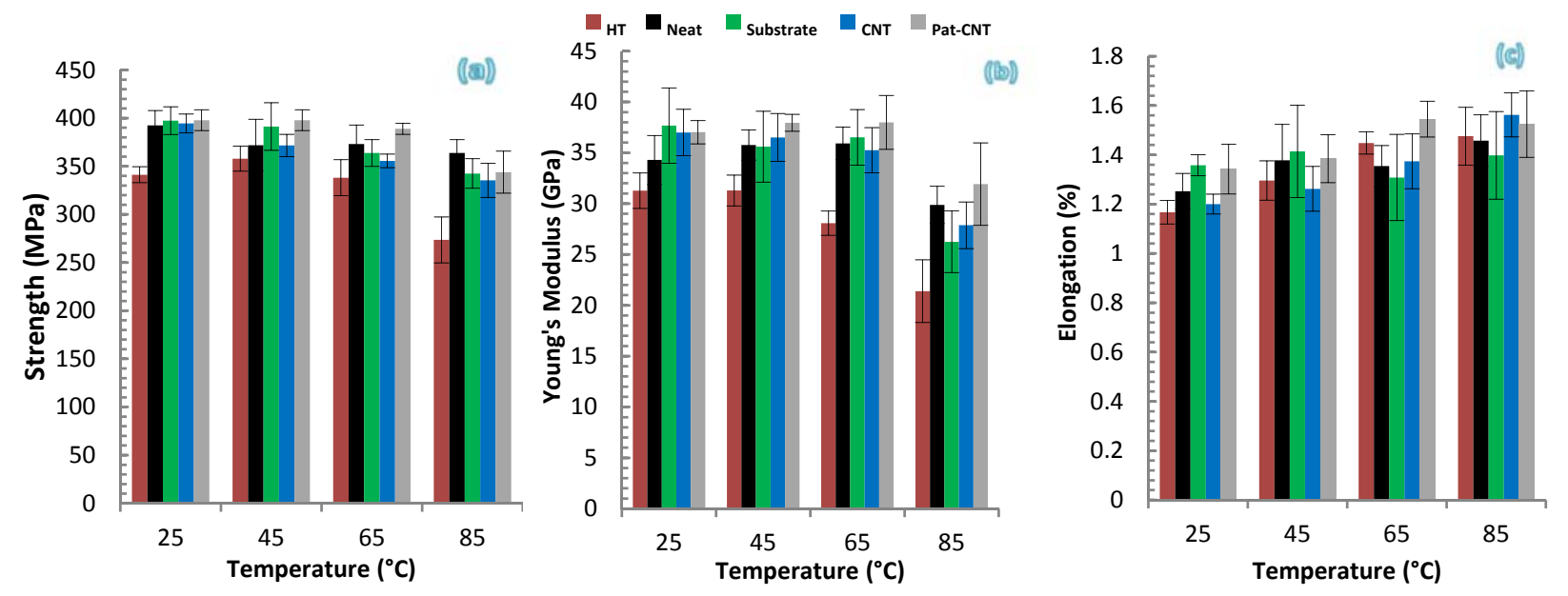

Figure 4. Tensile mechanical properties of the different composites configurations at different temperatures, (a) Strength, (b) Elastic modulus, and (c) Elongation to failure. 

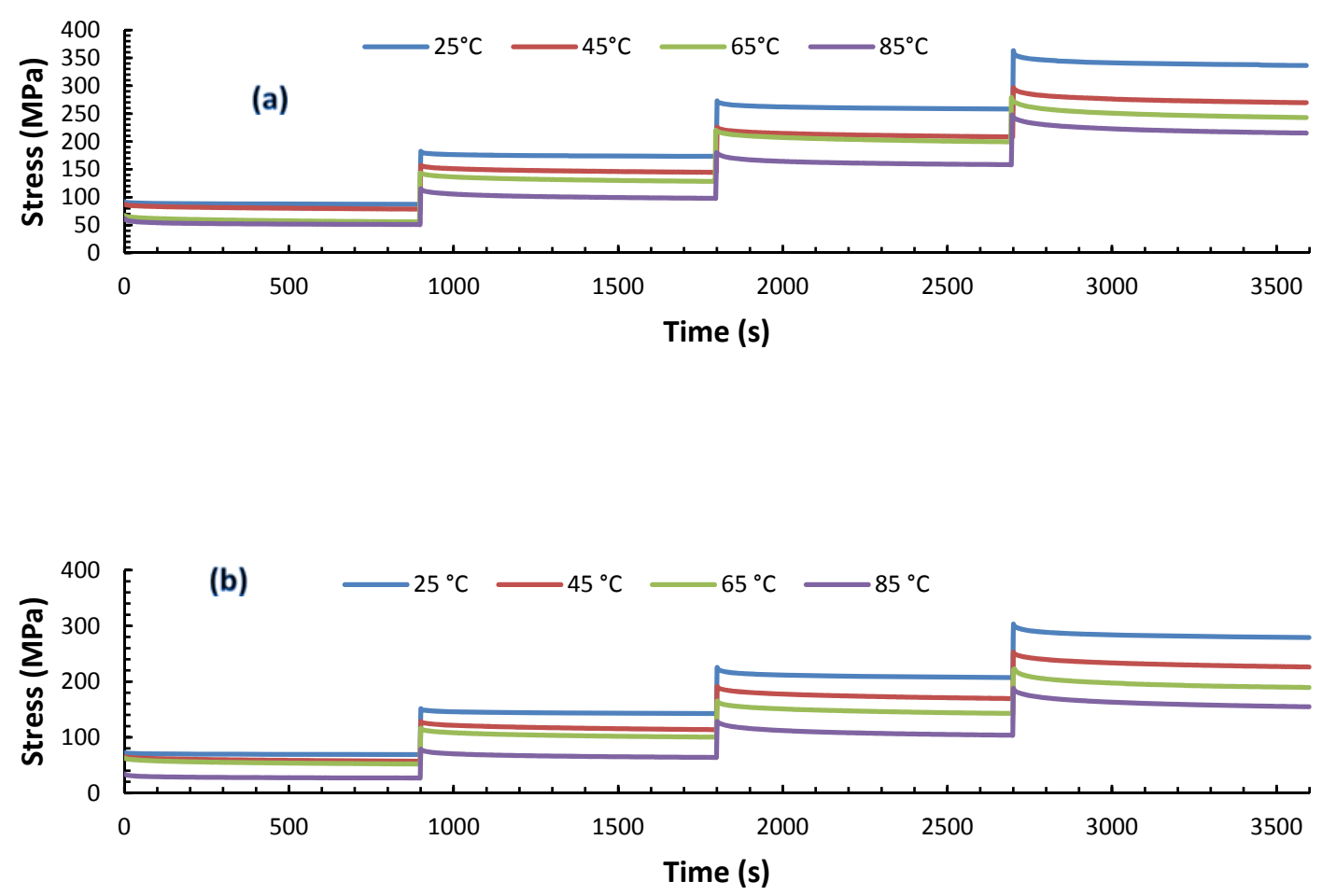

(c)
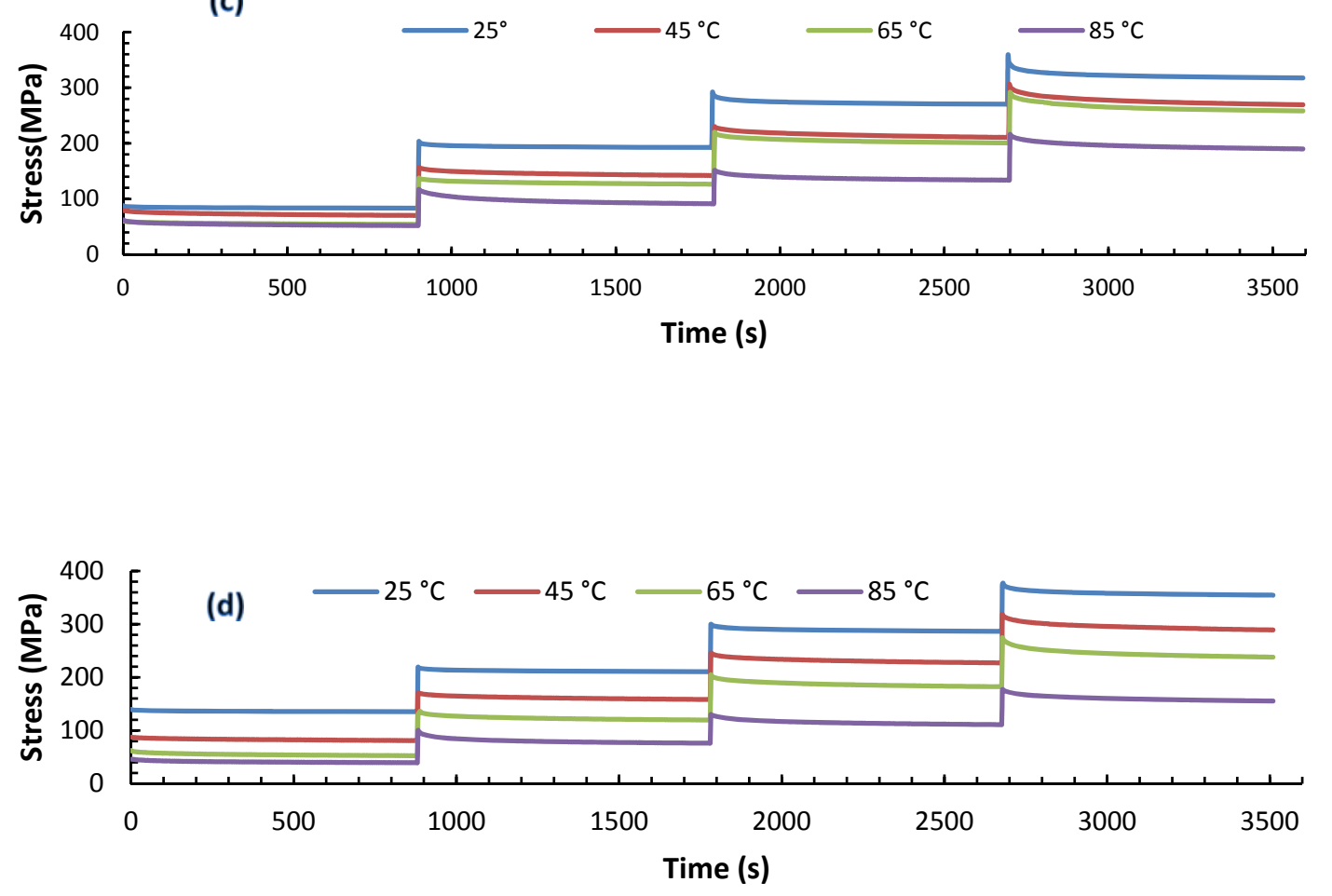


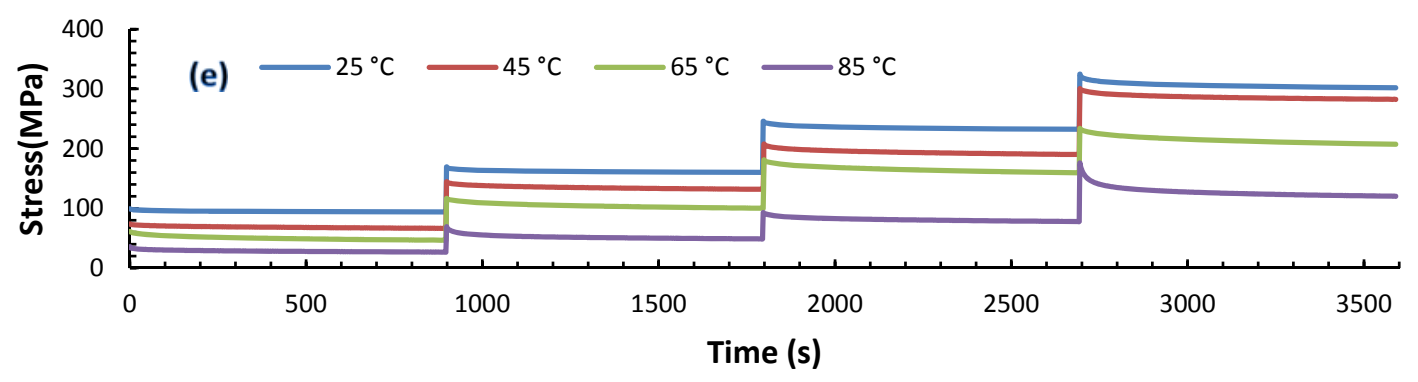

Figure 5. Stress relaxation test results for the (a) Neat (b) HT, (c) Sub, (d) CNT and (e) Pat-CNT composite samples at different temperatures. 

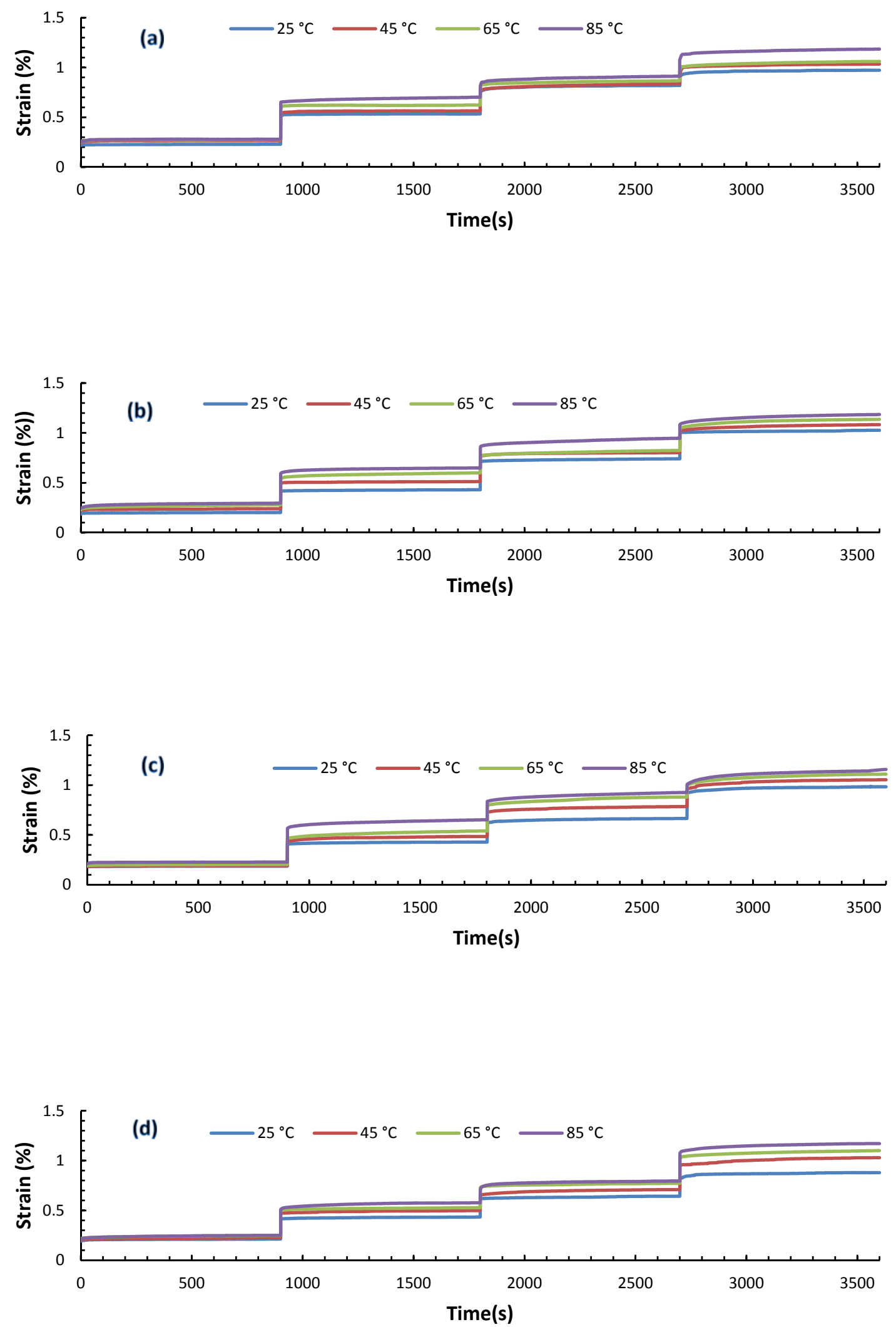


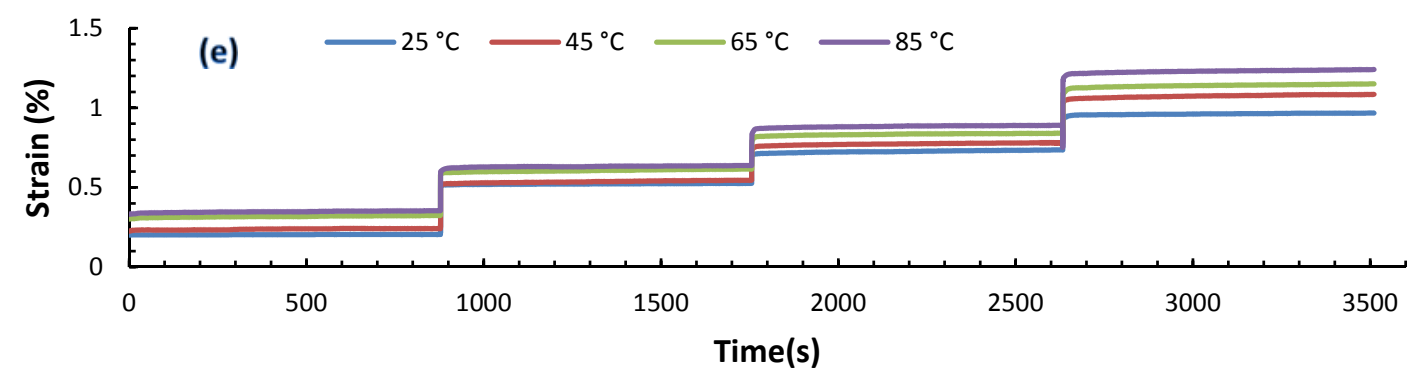

Figure 6. Creep test results curves for the (a) Neat (b) HT, (c) SUB, (d) CNT and (e) Pat-CNT composite samples at different temperatures 


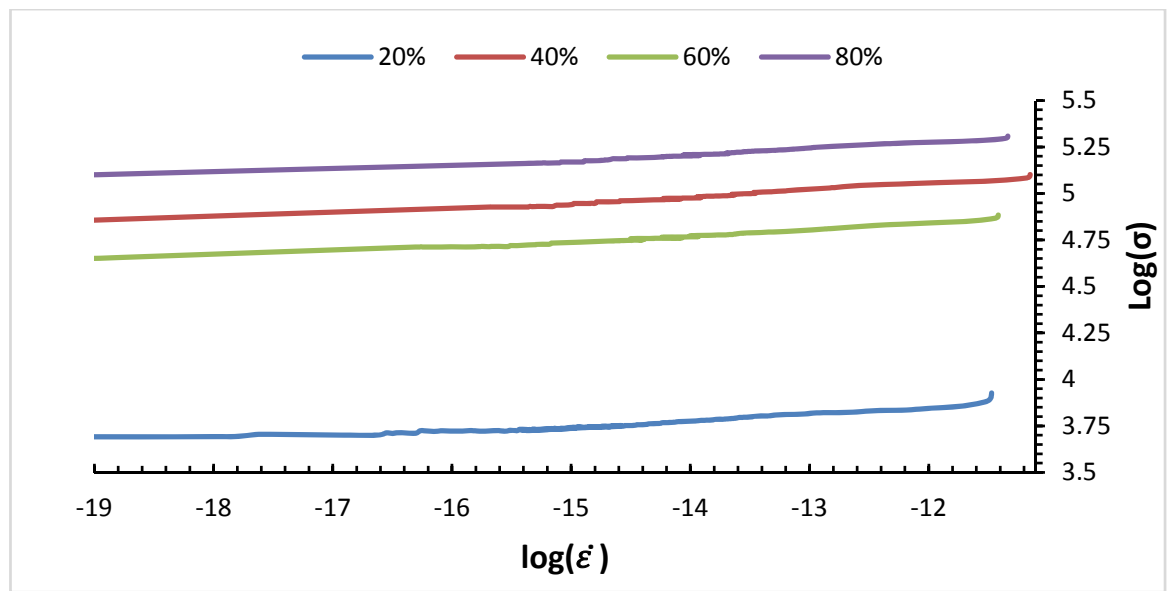

Figure 7. $\log (\sigma)-\log \left(\dot{\varepsilon}^{v p}\right) \quad$ for the $\mathrm{CNT}$ composite sample at $85^{\circ} \mathrm{C}$. 


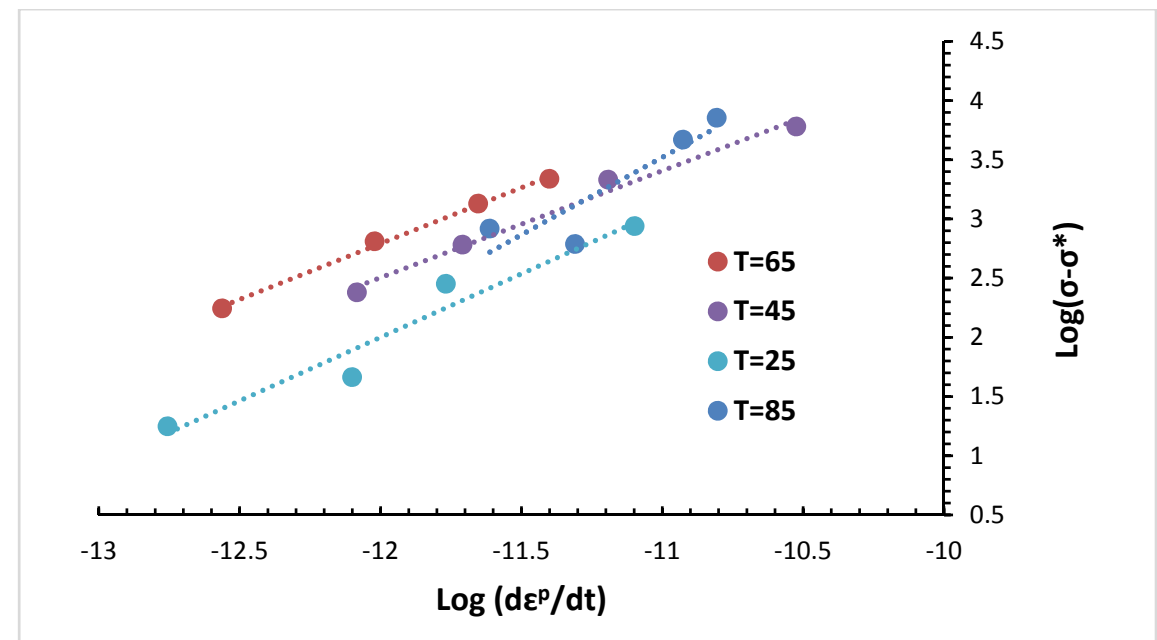

Figure 8. A sample plot of $\log \left(\sigma-\sigma^{*}\right)-\log \left(\dot{\varepsilon}^{p}\right)$ for CNT sample at different temperatures. These curves are used to determine the materials constants $K$ and $m$ at each temperature (overstress is in MPa). 


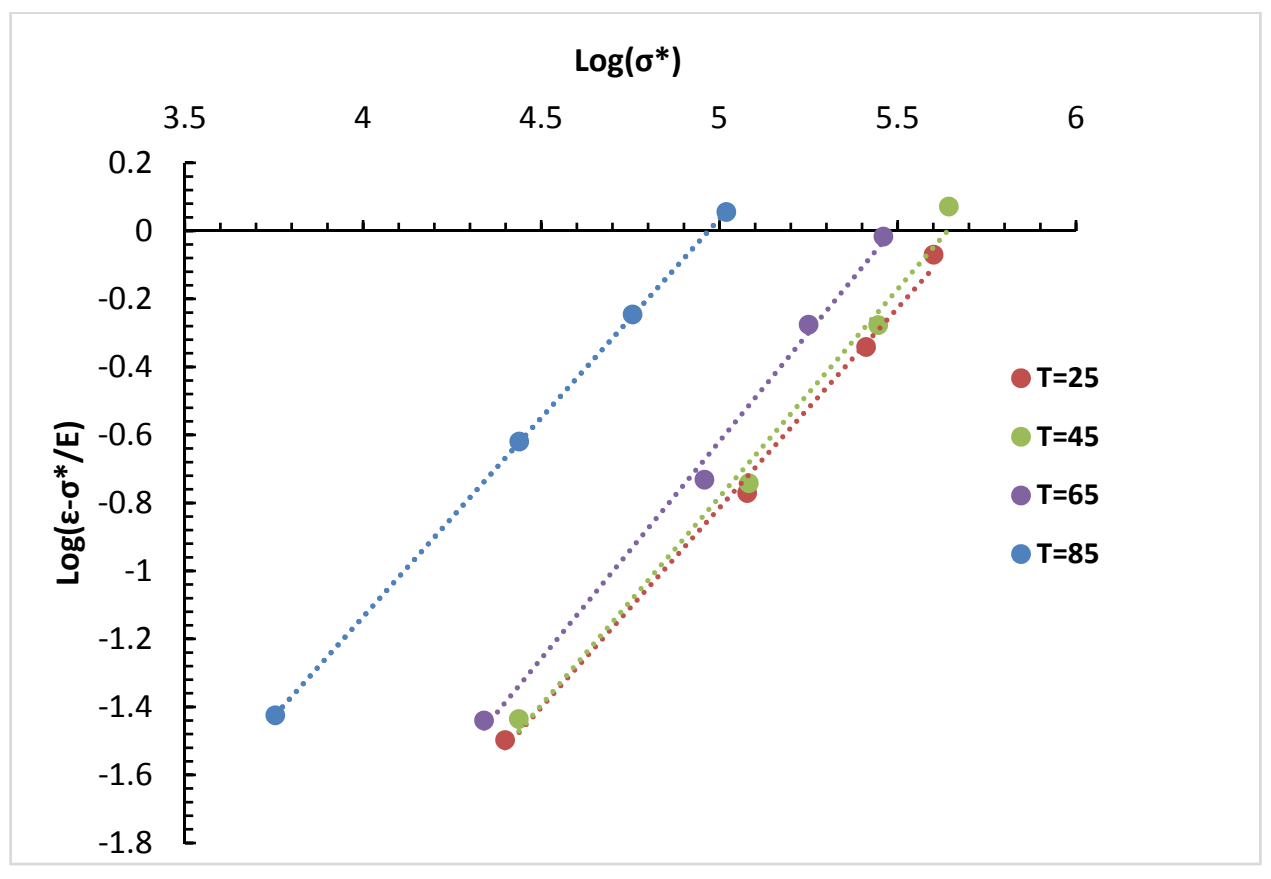

Figure 9. A sample plot of $\log \left(\varepsilon-\sigma^{*} / E\right)-\log \left(\sigma^{*}\right)$ for CNT sample at different temperatures.

These curves are used to determine the material constants $\boldsymbol{A}$ and $\boldsymbol{n}$ at each temperature (Quasistatic stress is in MPa). 


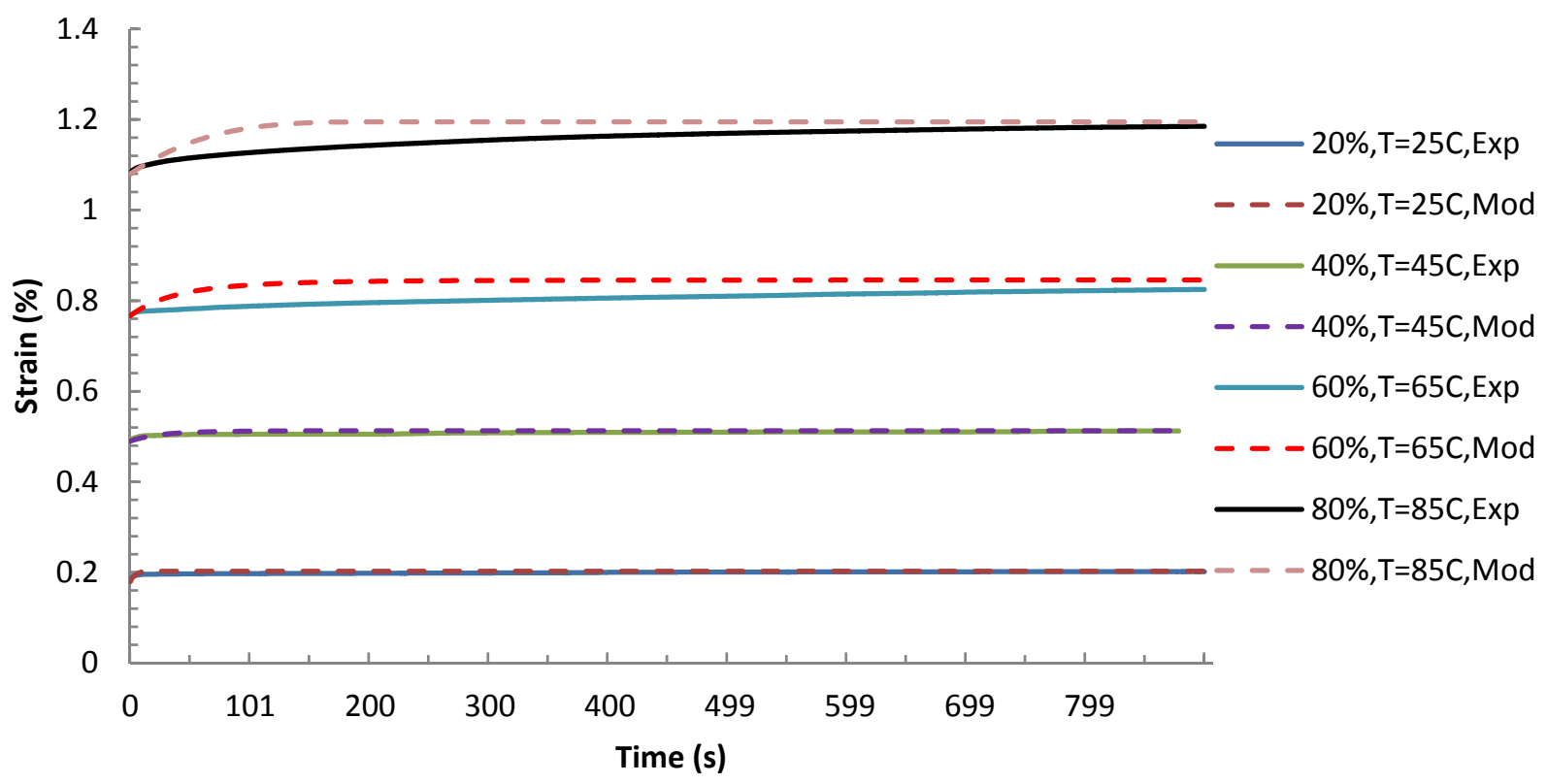

Figure 10. A sample plot of experimental data versus model prediction for the HT composite sample at four different temperatures and load levels. 


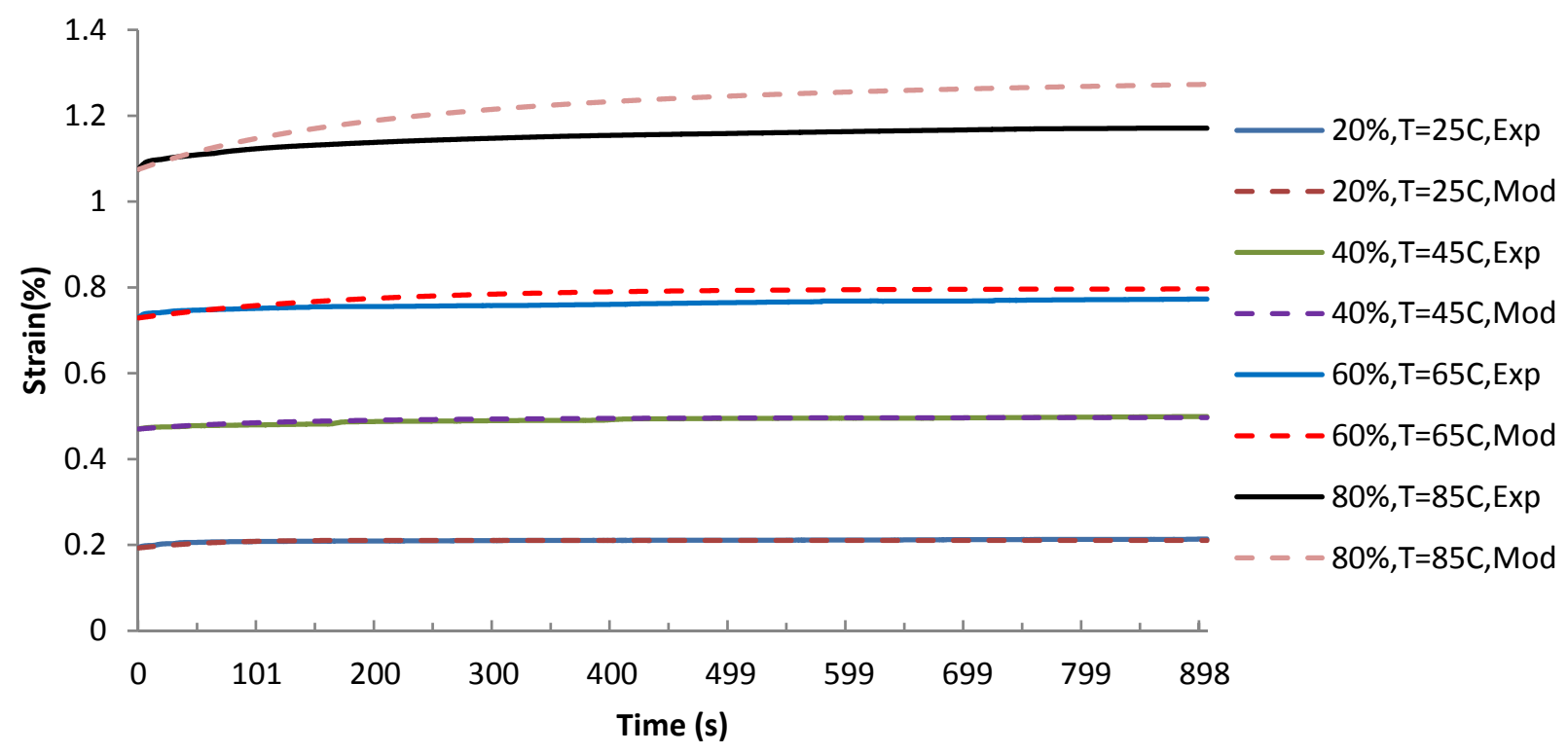

Figure 11. A sample plot of experimental data versus model prediction for the CNT composite sample at four different temperatures and load levels. 


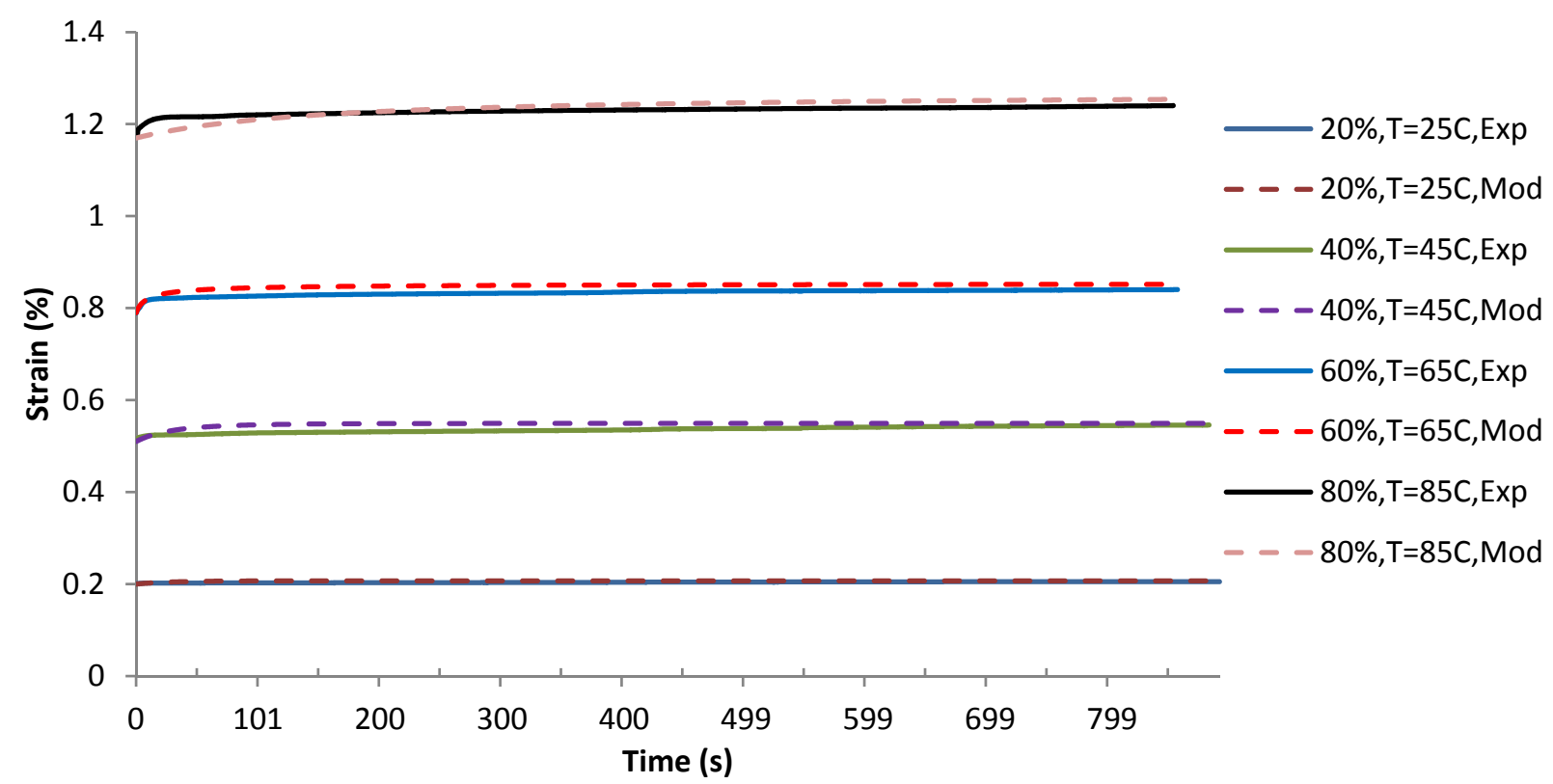

Figure 12. A sample plot of experimental data versus model prediction for the Pat-CNT composite sample at four different temperatures and load levels. 


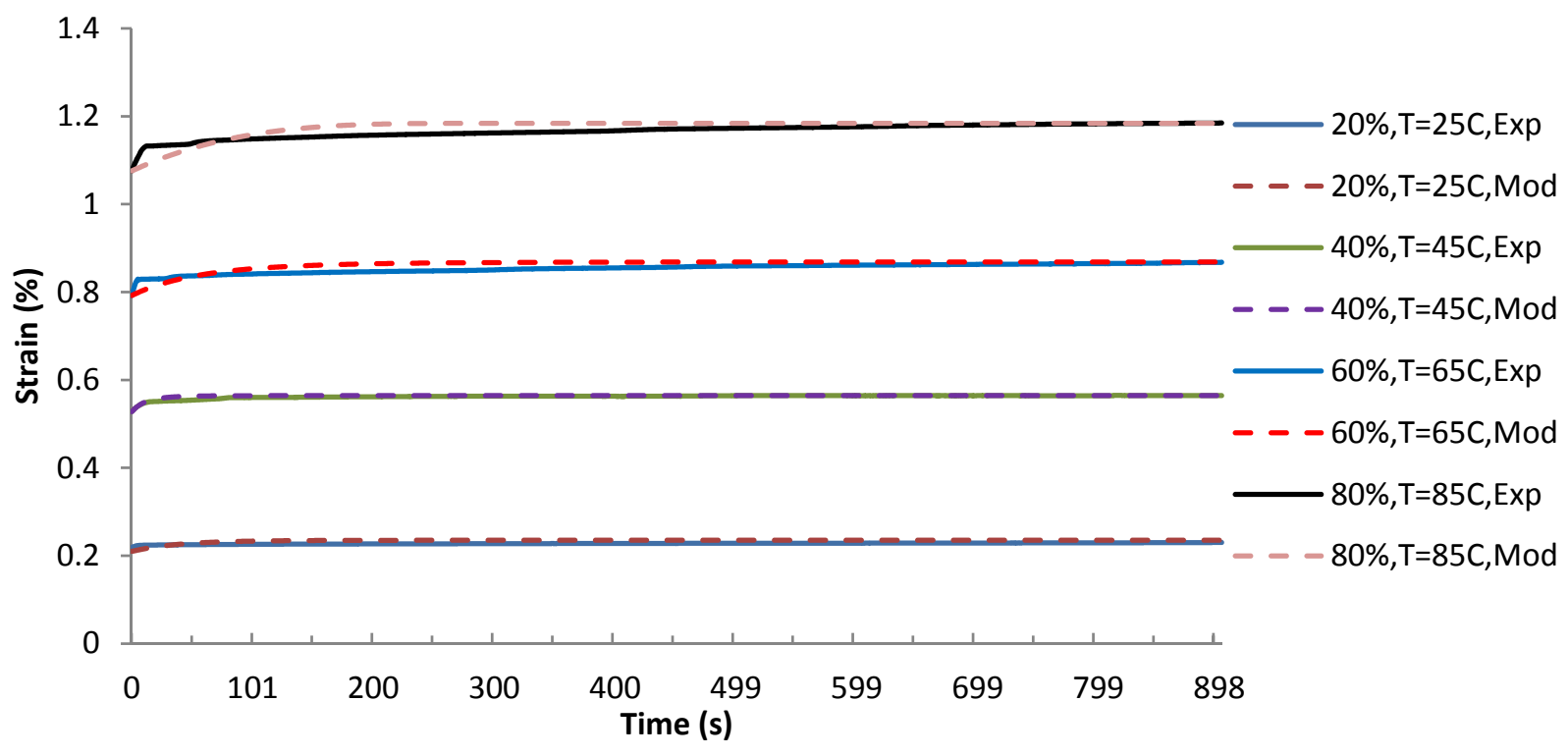

Figure 13. A sample plot of experimental data versus model prediction for the NT composite sample at four different temperatures and load levels. 


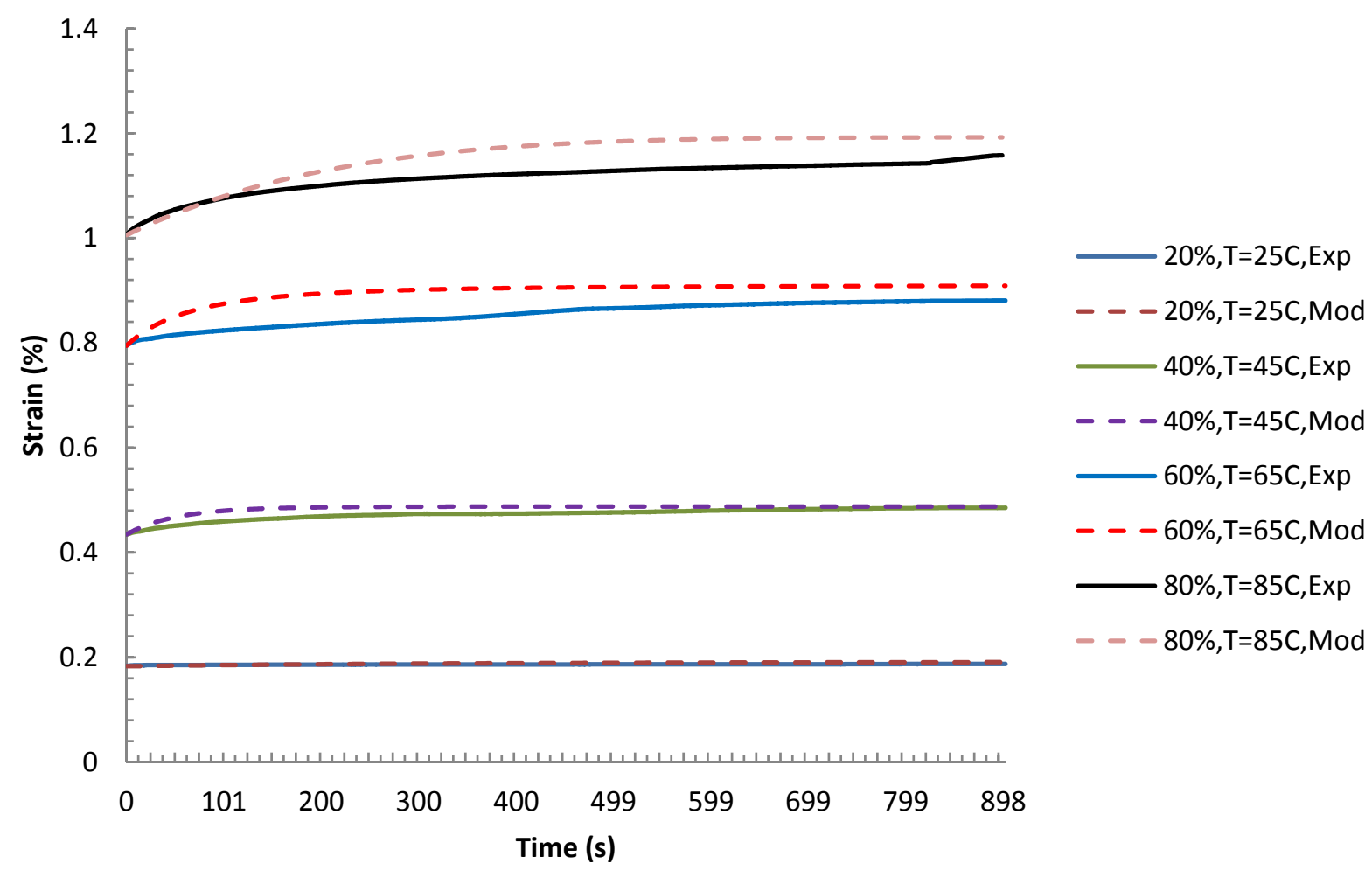

Figure 14. A sample plot of experimental data versus model prediction for the SUB composite sample at four different temperatures and load levels 